\title{
ENCUENTROS Y DESENCUENTROS DE LAS ÓRDENES MILITARES EN LAS GUERRAS DE FRONTERA ENTRE Castilla y Portugal en el siglo XIV
}

\author{
JUAN BOIX SALVADOR ${ }^{1}$ \\ Universidad Autónoma de Madrid
}

Recibido: 15 de junio de 2020

Aceptado: 22 de julio de 2020

\begin{abstract}
Resumen
Este trabajo pretende exponer los encuentros, amistosos o no, entre las órdenes militares castellanas y portuguesas en su integración en las huestes de esos reinos, en el siglo XIV. Desarrollaremos la presencia e intervención de las órdenes militares en las guerras de desgaste o de frontera entre los dos espacios, fruto de la política de las respectivas monarquías, en la pretensión de imponer sus criterios y su poder en esas relaciones. Igualmente, se observa la actitud de las dos Coronas con las órdenes, en su deseo de control y de dominio de las mismas, así como las consecuencias de esos conflictos en el ámbito de la frontera.
\end{abstract}

\section{Palabras clave}

Órdenes militares, reinos y dinastías de Castilla y Portugal, guerra de fronteras, control de las órdenes, consecuencias en la frontera.

\begin{abstract}
This work aims to show the encounters, whether friendly or not, between the Castilian and the Portuguese military orders throughout their integration into the hosts of those kingdoms in the fourteenth century. We study the presence and intervention of the military orders in the wars of attrition or border wars between both spaces. Those wars were the product of the policy in the respective monarchies, which claimed to impose their criteria and their power in their relations. Likewise, the desire of both Crowns to control and dominate the orders can be observed, as well as the consequences of these conflicts at the border.
\end{abstract}

\section{Keywords}

Military orders, kingdoms and dynasties of Castile and Portugal, border war, control of orders, consequences at the border.

\footnotetext{
Área de Historia Medieval. Departamento de Historia Antigua, H. Medieval, Paleografía y Diplomática. Facultad de Filosofía y Letras. Universidad Autónoma de Madrid. Correo electrónico: delboj6@gmail.com. ORCID: https://orcid.org/0000-0002-0646-7213.
} 


\section{Résumé}

Ce travail a pour objet d'exposer les contacts, amicaux ou non, entre les ordres militaires castillans et portugais et leur intégration dans les hosts de ces royaumes au XIV siècle. Nous soulignerons la présence et l'intervention des ordres militaires dans les guerres d'usure ou de frontière entre les deux espaces, fruit de la politique des monarchies respectives, dans l'ambition d'imposer leurs critères et leur pouvoir dans ces relations; de même, l'attitude des deux couronnes à l'égard des ordres, dans le but de les contrôler et de les dominer, ainsi que les conséquences de ces conflits dans le contexte de la frontière.

\section{Mots clés}

Ordres militaires, royaumes et dynasties de Castille et du Portugal, guerre de frontière, contrôle des ordres, conséquences à la frontière.

\section{Introducción}

Tanto Castilla como Portugal estuvieron en guerra en el siglo XIV en el que, indudablemente, para Castilla la guerra contra los musulmanes ocupaba un primer nivel, aunque también contaban las contiendas con Aragón o Navarra.

En época medieval no había ejércitos permanentes; el rey debía de convocar a sus vasallos para cubrir sus necesidades guerreras. En Castilla, las reformas de su ejército en el siglo XIV respondían a la voluntad de la monarquía por fortalecer el poder real, por lo que se aumentaron los efectivos de la mesnada real, organizada en capitanías de trescientas lanzas cada una, en tiempos de Enrique III (1390-1406). Idéntico proceder ocurría en las tropas no permanentes de los vasallos del rey. En la Cortes de 1338, de 1387 y de 1390, se intentaría regular las aportaciones de cada uno de ellos, para evaluar el número de lanzas. En estas últimas, las de Guadalajara, se instauró "un sistema de alardes, esperando así alcanzar una fuerza de cuatro mil quinientas lanzas castellanas, mil quinientos jinetes y mil ballesteros. La monarquía tenía así un número aceptable y prefijado de vasallos nobles bien armados, equipados y disponibles" ${ }^{\prime 2}$. En total, unos dieciséis mil combatientes.

Podríamos encuadrar en este apartado a las órdenes militares, pues eran milicias bien preparadas, equipadas y entrenadas para cualquier tipo de combate y siempre disponibles, aunque para ello tuvieran que efectuar levas en sus señoríos; eran parte de esos "ejércitos particulares a partir de sus propios vasallos solariegos". Según Ladero Quesada, en el período en que los efectivos nobiliarios alcanzarían su mayor expresión numérica -1478-1489-, las mesnadas de los nobles eran de siete mil hombres de armas y jinetes, mil doscientos ballesteros, cuatro mil cien peones lanceros y cuatrocientos veinticuatro espingarderos. Las cuatro órdenes militares, suministraban dos mil trescientos jinetes, quinientos a seiscientos ballesteros, dos mil cuatrocientos lanceros y

\footnotetext{
2 García Fitz, "Las guerras de cada día", pp. 154-156. "En las cortes de Burgos de 1338, Alfonso XI aprobó una regulación según la cual cada vasallo debía servir con caballo y equipo de caballero y con dos peones - un ballestero y un lancero- por cada 1.100 mrs. que recibiese".
} 
trescientos veintiséis espingarderos. $\mathrm{O}$ sea, un total de doce mil setecientos en el grupo de los nobles y cinco mil quinientos de las órdenes militares, es decir, un total de algo más de dieciocho mil hombres ${ }^{3}$.

El rey João I de Portugal (1385-1430), pretendía que la corona portuguesa debía tener una fuerza armada permanente de tres mil doscientas lanzas, repartidas entre la nobleza y las órdenes militares. Así, la alta nobleza debía contribuir con quinientas lanzas, la pequeña nobleza con dos mil trescientas sesenta y las órdenes militares con trescientas cuarenta: la orden de Cristo con cien, igual que Santiago, Avis con ochenta y el Hospital con sesenta ${ }^{4}$. Aunque esa cifra se pudo sobrepasar, pues "en el alarde llevado a cabo en Valariça, en mayo de 1386, D. João comprobó que se encontraban allí cuatro mil quinientas lanzas de caballeros y escuderos, además de muchos ballesteros y peones. Lo que representaría unos efectivos entre diez y doce mil combatientes"s. A la llegada de las tropas del duque de Lancaster, el ejército luso conseguía reunir dos mil seiscientas lanzas y seis mil peones ${ }^{6}$.

Los efectivos mostrados en estos datos no corresponden solo a los freires de las órdenes, dado que, en la conquista de Sevilla en 1248, en la que participaron todas las órdenes castellanas, incluida las del Hospital y del Temple y la portuguesa de Avis, sus huestes no sobrepasarían los ciento cincuenta-doscientos hombres7. En 1336, "los maestres de Santiago y Calatrava movilizaron a su costa mil hombres a caballo, que posiblemente fueran mercenarios, para luchar contra don Juan Manuel"s.

Podemos ahondar un poco más en esas cifras, pues en las definiciones de las órdenes se puede observar que los caballeros tenían a su servicio un cierto número de auxiliares.

Si sumamos todos los efectivos, en la orden de Cristo, a los 69-71 caballeros habría que añadir 6 sargentos y 58 auxiliares; es decir un total de 133 a 135 hombres. En Santiago a los 61 caballeros, habría que añadir 4 a 6 sargentos y 30 auxiliares, con un total de 95-97. Para Avis, serían 51, 4 y 11, con un total de 66. En cuanto al Hospital, si en 1262 los caballeros eran 21, ahora serían cercanos a los efectivos de Avis, pues en los inicios del Cuatrocientos había 50 caballeros y 25 del resto.

A estas fuerzas habría que agregar los vasallos de sus dominios, las milicias de los concejos locales, así como el reclutamiento de tropas mercenarias, especialistas como

\footnotetext{
LADERo, "Formación y funcionamiento de las huestes reales", p. 162.

4 García Fitz, "Las guerras de cada día", p. 270; Monteiro, A guerra em Portugal, pp. 81-83; Oliveira; Monteiro, Historia medieval de Portugal, p. 200.

5 García Fitz, "Las guerras de cada día", p. 264.

6 Ladero, "Formación y funcionamiento de las huestes reales", p. 163.

7 Ayala, Las Órdenes Militares Hispánicas en la Edad Media, p. 554.

8 Rodríguez-Picavea, Los Monjes Guerreros, p. 128.

9 Martins M, "As hostes das ordens militares em Portugal", vol. 1, p. 326-328; Martins M; Monteiro, "Portugal. II. The Late Middle Ages”, p. 221.
} 
ballesteros o antiguos soldados que estuvieran decididos a luchar de nuevo. Por ello, además, cada orden podía disponer entre uno y tres centenares de hombres de armas en cada operación militar. Así, en 1330 el maestre de Cristo, Martim Gonçalves, había reunido quinientas lanzas para participar en la campaña castellana de ese año, la conquista del castillo de Teba. Pedro I de Portugal (1357-1367) enviaría varias mesnadas de auxilio a su sobrino Pedro I de Castilla (1350-1369), con seiscientas lanzas en 1361 y trescientas en 1363, al mando de los maestres de Avis y de Santiago ${ }^{10}$.

Pero ¿cuál era el nivel de los ejércitos peninsulares en la Baja Edad Media? ¿Se habían quedado retrasados en su evolución, en comparación con los franceses e ingleses, que probaron nuevos métodos, nuevas técnicas, nuevos armamentos en la Guerra de los Cien Años ${ }^{11}$ ?

En el siglo XIV, los ejércitos castellanos y portugueses acelerarán su progreso por los contactos habidos con huestes formadas precisamente en la Guerra de los Cien Años. En la segunda batalla de Nájera, en 1367, junto a Pedro I encontramos las tropas del Príncipe Negro y en las de Enrique II (1367/1369-1379) las compañías blancas de Bertrand du Guesclin, que ya se habían enfrentado en Crécy o en Poitiers, unos años antes. Pero, no sólo ahí, sino que, en el verano de 1369, en la primera guerra fernandina, Enrique II en su campaña en el Miño y Tras-os-Montes iba acompañado por el condestable francés y sus tropas.

En la tercera guerra fernandina, en 1381-1382, el ejército luso estaba arropado por el inglés del conde de Cambridge, lo que posibilitaría su puesta al día y repercutiría en una mejor organización y conocimientos tácticos de las tropas del rey João I, traducido en las victorias de Atoleiros, Trancoso y Aljubarrota. La presencia de las huestes inglesas del duque de Lancaster en 1387 contribuyó al agiornamento del ejército portugués, que aplicaría esas técnicas en las incursiones en Castilla en la última década del siglo ${ }^{12}$. El ejército castellano no se quedó a la zaga del luso, sino que también evolucionó adecuadamente ${ }^{13}$.

Es interesante detenernos un momento en definir el concepto de lanza, que surgiría en el paso del siglo XIII al XIV. Era una unidad fiscal y militar al mismo tiempo que se relacionaba con la nueva y más eficaz organización de las órdenes militares, para atender a los llamamientos militares formulados por la realeza; no hay un criterio uniforme para describir las lanzas hispánicas ${ }^{14}$. Tal vez se tratase de unidades inferiores a la lanza borgoñona integrada por nueve hombres o la lanza francesa compuesta por seis hombres; quizás la lanza hispánica estuviera formada como mínimo por un caballero, equipado como caballería pesada y acompañado por otra montura ligera y de uno

\footnotetext{
Martins M, "As hostes das ordens militares em Portugal”, vol. 1, p. 334.

Monteiro, "Arcaísmo o modernidade no Exército Português", p. 259.

IBIDEM, pp. 262-263.

SOLER, La evolución del armamento medieval, pp. 170, 197-198 y 203-207.

4 Ayala, Las Órdenes Militares Hispánicas, pp. 555-557; Rodríguez-Picavea, Los Monjes Guerreros, pp. 139-140.
} 
a tres ayudantes. En Portugal "a cada lança correspondía un hombre de armas" fue hasta mediados del siglo XIV que en el ámbito hispánico la lanza se impuso como referencia militar básica para las movilizaciones.

Frente a la idea habitual de grandes combates o batallas campales en espacios abiertos, predominaron las guerras de desgaste, de posiciones o de fronteras, "guerra guerreada", con el propósito de arruinar el patrimonio del adversario por motivos económicos; así muchas de las veces los objetivos fueron puros $\operatorname{robos}^{16}$. No se necesitaban muchos efectivos, ni una gran logística, sino una preparación concreta para este tipo de operaciones y una rapidez de ejecución muy efectiva. Eran efectuadas por las guarniciones de los castillos fronterizos, y en ambos casos también por las órdenes militares y apuntaban a la destrucción de cosechas, al robo de ganados y de personas y al incendio y destrucción de habitaciones e infraestructuras.

Así, conviene definir el concepto de frontera en la Edad Media.

Durante mucho tiempo, frontera fue sobre todo sinónimo de frente de lucha contra los moros. O sea un límite fluido y oscilante, variable conforme las incidencias de la lucha entre cristianos y musulmanes, que avanzaría o retrocedería según los avatares de los combates... Con el fin de la reconquista ya no existía un "frente musulmán", pero... esas defensas muestran que para la monarquía existía una frontera en el Norte y en el Este ${ }^{17}$.

Igualmente,

la frontera ha sido siempre un espacio sensible a los períodos de elevada inestabilidad política... en relación con comunidades vecinas, en las que se pueden observar los cambios introducidos por el incremento de la guerra. Y aunque la frontera no es la guerra, sí lo es en las modificaciones de las estructuras producidas por los conflictos, relacionados con una intensa señorialización de los territorios, un proceso de fortificación defensivo y la inserción de los grupos sociales damnificados ${ }^{18}$.

La guerra degrada la frontera de manera evidente, pero no es la causa de la crisis, sino una manifestación de la misma: despoblación, abandono del campo, dificultades en la producción y en el suministro de alimentos y el consecuente desplome comercial, lo que acarrea un replanteamiento del conjunto de las actividades económicas, así como determina el modelo de sociedad y su evolución. Pero, la frontera no era sólo la gue-

\footnotetext{
Monteiro, A guerra em Portugal, p. 34, nota 37.

16 García Fitz, Ejércitos y actividades guerreras, pp. 45-47; Montaña, "E Levaram Captivos", p. 15.

17 Monteiro; Martins M, As Cicatrizes da Guerra, pp. 13-14 y 16.

18 Montaña, "E Levaram Captivos", p. 19.
} 
rra, sino que también "generó un régimen jurídico propio, con un fuerte componente económico, debido al flujo de productos y mercaderes"19.

La frontera castellano-portuguesa en la Edad Media se presentaba como el resultado de un complejo proceso, desde que quedaron fijadas las respectivas demarcaciones de soberanía de ambas monarquías en el tratado de Alcañices en 1297 entre D. Dinis de Portugal (1279-1325) y Fernando IV de Castilla (1295-1312). En todo caso será siempre un "espacio discutido", marcado por la presencia de fortalezas de gran valor estratégico, en manos de la nobleza o de las órdenes militares, con hombres de armas y prisioneros de guerra en el caso castellano o coutos de homiziados en el perímetro portugués, garantía para las monarquías de defensa del territorio ${ }^{20}$.

A mediados del siglo XIV se advierte el valor de la frontera con Castilla, reflejada en la trascendencia dada por la monarquía lusa a los castillos y fortalezas fronterizos, -el monarca mandaba reparar treinta y siete castillos en la frontera- hasta tal punto que aquellos que pertenecían a señores laicos o eclesiásticos "foram colocados sob o poder regio o foram submetidos a um novo regime de tenência mais favorábel ao soberano" ${ }_{21}$. Los conflictos fronterizos se localizarán en unos dominios bien definidos: el Miño en el norte, en la Beira-Duero en el este, con Salamanca, Ciudad Rodrigo, Zamora y Toro y en el Alentejo-Guadiana, con Elvas, Badajoz y en territorios de las órdenes de Alcántara, Santiago, Avis y el Hospital, en el sur ${ }^{22}$. En Portugal, a mediados del siglo $\mathrm{XV}$, se contabilizaban cuarenta plazas fuertes en la frontera, de las ciento diecinueve fortalezas en el reino, o sea un $34 \%$; la mitad de las fronterizas estaban en el Alentejo ${ }^{23}$. Los soberanos castellanos confiaban en los fronteros y en los adelantados para vigilar la frontera, mantener las defensas y las fortalezas de la misma y organizar y concretar operaciones militares. Así mismo, la monarquía portuguesa había dado una gran importancia a la protección de "una frontera terrestre luso-castellana con más de mil quinientos kilómetros de extensión", en la que jugaban un papel primordial los fronteros mayores y los alcaldes mayores de las fortalezas dispuestas estratégicamente a lo largo de dicha frontera ${ }^{24}$. Para ello, disponían de unos efectivos de entre 100 y 250 lanzas.

En los dos reinos, los fronteros eran nombrados entre los miembros de la casa real, de la alta nobleza o de las órdenes militares. Así, por ejemplo, en el reinado de Fernando I (1367-1383), en 1369, "los fronteros mayores entre Tajo y Guadiana eran sus hermanastros Juan y Dinis de Castro". Igualmente, lo serían “el maestre de Avis, Vasco Afonso, en 1325 en Ouguela, plaza que pertenecía a la orden; Estêvão Gonçalves, maestre de Cristo, en 1355 en Porto, donde fue sustituido por prior del Hospital, Álvaro Gonçalves Pereira”. En 1383, "D. Leonor de Telles enviaba a João, maestre de Avis, como frontero entre Tajo y Guadiana, con instrucciones para defender las tierras de su maestrazgo, así

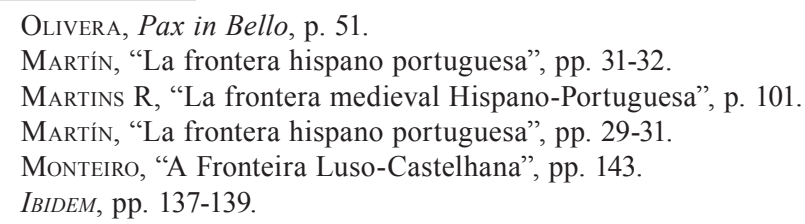


como çertas villas e castellos darredor" ${ }^{25}$. También era frontero mayor en 1387, Nuno Álvares Pereira, condestable del reino. En Castilla, el conde de Feria y los maestres de Santiago y de Alcántara serán fronteros con Portugal en este siglo.

A señalar la trascendencia de la frontera para João I en la estrategia de las guerras lusocastellanas, en el último tercio del siglo XIV. Después de Aljubarrota, sería un factor de presión sobre el adversario, ya que Juan I de Castilla (1379-1390), no abandonó nunca la idea de volver a Portugal ${ }^{26}$. Es lo mismo que harían los monarcas castellanos, desde Alfonso XI (1312-1350) hasta los Reyes Católicos (1474-1504/1516).

En Castilla, las órdenes militares participarán en la vida política del reino, formando parte de una u otra de esas facciones de los siglos XIV, en apoyo o en contra del monarca, según los bandazos de esa política, los intereses de sus dignatarios y de sus resultados. El profesor Ayala evoca la secularización de las órdenes militares castellanas como fundamental para entender su evolución; es decir, se apartarán de sus misiones religiosas para abrazar los temas políticos y aristocráticos. Así, establece

tres momentos clave de ese cambio: primero la desactivación del factor islámico peninsular, después de la batalla del Salado, en 1340 y la toma de Algeciras en 1344; segundo la guerra civil en Castilla entre 1360 y 1369. Un tercer punto es la guerra de los Dos Pedros, entre 1356 y 1365, en el contexto de la Guerra de los Cien Años ${ }^{27}$.

Este proceso arranca en la segunda mitad del siglo XIII y será más evidente en el siglo $\mathrm{XIV}$, con el intervencionismo de los monarcas en las órdenes y el interés también de la nobleza en su control como símbolo de poder, abandonando, parcialmente, su razón de ser: la lucha contra los musulmanes. En Castilla y en Portugal, todos los monarcas se involucraron en el nombramiento de los maestres de las órdenes.

En las órdenes castellanas, los dignatarios serán miembros de la alta nobleza, aunque, por ejemplo, "la mayoría de los freires de Calatrava venían de la baja nobleza, muchos procedentes de las oligarquías urbanas. La alta y la media nobleza controlarían el triunvirato de poder de la orden -maestre, comendador mayor y clavero- y las encomiendas más importantes" ${ }^{28}$. En Portugal, serán personajes de la familia real o de linajes muy próximos ${ }^{29}$. En las órdenes portuguesas, observamos que "a partir de finales del siglo XIV se detecta un peso creciente de los elementos salidos de los linajes de la pequeña y mediana nobleza, en tanto se volvían minoría los caballeros con apellidos con orígenes más modestos", aunque los maestres seguirán siendo cercanos a la monarquía ${ }^{30}$.

\footnotetext{
IBIDEM, p. 139; Monteiro, A guerra em Portugal, p. 80.

Monteiro; Martins M, As cicatrizes da guerra, p. 145; Monteiro, "A Fronteira Luso-Castelhana", p. 145

Ayala, "Pedro I y las órdenes militares", pp. 63-92.

Rodríguez-Picavea, "Caballería y nobleza en la Orden de Calatrava", p. 731.

9 Oliveira; Monteiro, Historia medieval de Portugal, pp. 200-201.

30 Fernandes; Oliveira, "Las Órdenes Militares", p. 151.
} 
La segunda mitad del siglo verá la llegada de dos nuevas dinastías, de origen distinto. En Castilla será después de una guerra civil, con los Trastámara desde 1369 y en Portugal con una guerra civil y una de independencia, con los Avis a partir de 1385. Ambas generarán una larga serie de conflictos que no fueron resueltos hasta las paces de Medina del Campo-Almeirim de 1431-1432.

La historiografía hispano-portuguesa se ha interesado sobremanera por las relaciones entre Castilla y Portugal en este siglo, los conflictos y los acuerdos, en particular la crisis del 1383-1386. En cambio, el papel de las órdenes militares se ha enfocado desde casos puntuales en el marco de los enfrentamientos, sobre todo en Extremadura o el Alentejo, salvo en las Crónicas de las órdenes. Sin pretender, ni mucho menos, haber sido exhaustivos, se plantea su actuación en el siglo XIV, en las contiendas de los dos reinos.

\section{Injerencia de las monarquías en las órdenes militares}

Desde su creación, las órdenes militares sufrirán la intromisión de los monarcas, en su afán de dominarlas y de nombrar a los cargos más importantes, colocando en ellos a personas allegadas, miembros de la familia real o de los linajes más importantes.

En 1319, D. Dinís conseguirá la fundación de la orden de Cristo, intervenida por el rey desde su inicio y establecida en Castro Marim ${ }^{31}$. Antes, la orden de Santiago portuguesa se había escindido de la castellana, durante el maestrazgo castellano de Pedro Fernández Mata, al obtener del papa Nicolás IV el nombramiento de un maestre propio, por la bula Pastoralis officii, de septiembre de $1288^{32}$. Aunque Celestino V revocó la bula en septiembre de 1294, la obediencia de los freires portugueses ya no se volvió a conseguir, al ser confirmada por Bonifacio VIII en noviembre del mismo año.

La monarquía lusa dominará también la orden de Avis, inmiscuyéndose en sus asuntos internos. En torno a 1300, la familia real donaba a Avis diversos lugares, como Elvas o Noudar. El rey se entrometió en la elección de un nuevo maestre en 1311, al haber elegido los freires como maestre a Garcia Peres do Casal, mientras otros lo hacían con el comendador mayor Aires Afonso, pues, decía, "a orden de Avis he cousa minha e dos reys que forom ante de mim e que depos mim am de viir pera mandarmos sobre los beens della e sobre las Comendas..." ${ }^{33}$, lo que no se hizo pacíficamente. También lo haría en 1316 al nombrar maestre a Gil Martins, "transferido" como maestre a la orden de Cristo en 1319 y la elección en Avis de Vasco Afonso. Se volvería a producir en 1321, al presentar al papa a su candidato a maestre, João Lourenço, sin dejar la elección a los freires de la orden. Así, la orden de Calatrava la visitaba en 1316, debido a la "discordia que entre ellos avia sobre elección del Maestre" ${ }^{34}$. Esta dependencia de

\footnotetext{
Pina, Crónica de D. Dinis, pp. 80-81 y 241-262.

2 GonZÁlez, "La reacción oligárquica frente al poder de las monarquías", p. 622.

33 Cunha, "A Ordem de Avis e a monarquia portuguesa", p. 121; VAsconcelos, "Nobreza e Ordens Militares", pp. 33 y 37.

34 Cunha, "A Ordem de Avis e a monarquia portuguesa", p. 121.
} 
Calatrava planteaba a los reyes portugueses y a la propia orden, el saber qué camino seguir en caso de una confrontación entre los dos reinos.

Por ello, los monarcas se empeñarían en dispensarlas de esa obediencia; se conseguiría la elección de un maestre de Avis sin el consentimiento de Calatrava en junio de 1330, con sólo la del arzobispo de Braga y con autorización papal. Si bien "Calatrava mantendría sus derechos hasta 1391, en que se les retirarían temporalmente, como consecuencia del Cisma de Occidente, que recobrarían en 1436 en el Concilio de Basilea, aunque Avis no sería muy receptiva al control de la orden castellana" ${ }^{35}$.

Así mismo, D. Dinis, que ya había tenido problemas con la orden del Hospital al incorporar los bienes de los templarios, "recortó algunos de los derechos de los hospitalarios, haciendo que se emitieran una serie de sentencias contrarias a los intereses de los freires, tanto en término de impuestos como en la jurisdicción ejercida en ciertas tierras" ${ }^{36}$. Afonso IV (1325-1357) quería evitar, como en otros reinos peninsulares, los envíos de dinero al convento de Rodas; así, en los primeros años de su reinado, se apoderó de esa contribución. Así mismo, cuando el Gran maestre de Rodas eligió como prior de la orden a Álvaro Gonçalves Camelo, Fernando I impuso su criterio y se designó a Pedro Álvares Pereira, hijo bastardo del anterior prior Álvaro Gonçalves Pereira ${ }^{37}$.

Pero, no sólo la monarquía quiso controlar y dirigir las órdenes, sino que también quisieron hacerlo los linajes más importantes del reino. Así, los Pimentel coparon las dignidades, haciendo de los cargos una cuestión de familia. Lo contemplamos desde Estevão Vasques Pimentel, como prior del Hospital, desde 1306 a 1336 y que será embajador en Aviñón. Seguimos con Lourenço Eanes Pimentel, maestre de Santiago desde 1314, a quien le sucedió Lourenço Vásques Pimentel; en 1359, otro Pimentel sería comendador mayor de la orden. Por último, João Rodrigues Pimentel sería maestre de la orden de Avis, entre 1342 y 1351. Este linaje estaba emparentado al de los Pereira, así un sobrino nieto de Estavão Pimentel e hijo bastardo de Gonçalo Pereira arzobispo de Braga, Álvaro Gonçalves Pereira le sustituirá al frente del Hospital a su muerte. Hijos de éste serían el condestable Nuno Álvares Pereira y el prior del Hospital Pedro Álvares Pereira $^{38}$. Aparecerá desde 1387 como maestre de la orden portuguesa de Santiago el primer miembro del linaje Vasconcelos, Mem Rodrigues de Vaconcelos, que mandaría el Ala de los Enamorados en la batalla de Aljubarrota. Este cargo permitirá la extensión del linaje en numerosas encomiendas de la orden ${ }^{39}$.

Las órdenes castellanas sufrían idénticas actuaciones. Así, en la orden de Calatrava, asoma el linaje Guzmán desde 1385, con el maestrazgo de Gonzalo Núñez de Guzmán, así como dos claveros homónimos, Ramiro Núñez de Guzmán, sin olvidar a dos comendadores mayores, como Juan Ramírez de Guzmán y Fernán Gómez de Guzmán

\footnotetext{
5 Cunha, "A filiação da Ordem de Avis em Calatrava", p. 321.

36 Costa, P, “As adaptações das Ordens Militares”, pp. 147-148.

37 Costa P, “A Ordem Militar do Hospital em Portugal”, p. 194; VAsconcelos, "Nobreza e Ordens Militares", p. 52.

38 SousA, "Memória familiar e ordens militares", pp. 40-42.

39 VAsconcelos, "Os Vasconcelos e as ordens militares", pp. 250-251.
} 
y varios comendadores. Otro linaje importante fue el de Padilla, con el maestre Diego García de Padilla y otros dignatarios, ya en el siglo XV. Otros linajes, como Godoy, con el maestre Pedro Muñiz de Godoy o Sandoval, con el comendador mayor Gutierre Díaz de Sandoval. No podemos dejar de mencionar al linaje Girón: un Pedro Girón fue comendador santiaguista de Martos; pero su elemento más relevante sería Pedro Téllez Girón, maestre en el siglo XV. Por último, los linajes Villalobos, con Fernando Rodríguez Villalobos, clavero de Calatrava y maestre de Alcántara; Cárdenas, con el clavero García López de Cárdenas; Carrillo que tendría a Lope Carrillo como comendador mayor ${ }^{40}$.

Las órdenes militares intervendrán en la política de Castilla durante el reinado de Fernando IV y la minoría de edad de Alfonso XI, para conseguir la paz en sus territorios. Para ello "concertarán entre las órdenes de Santiago, Calatrava y Alcántara una carta de Hermandad, en marzo de 1313, junto a sus dignatarios y caballeros, por la que acordaron hacer hermandad y ordenamiento al servicio del rey Alfonso". Hermandad que los maestres García Fernández de Santiago, García López de Padilla de Calatrava y Suer Pérez Maldonado de Alcántara, volverían a establecer en abril de $1318^{41}$.

Alfonso XI quiso dominar las órdenes militares; por ello, los maestres fueron parientes o afines a Leonor de Guzmán, favorita del monarca. En 1318 fue depuesto el maestre de Alcántara Ruy Vázquez, por problemas con los freires de la orden ${ }^{42}$. En mayo de 1337 era desposeído del maestrazgo de Alcántara Ruy Pérez Maldonado y nombrado y luego elegido el despensero mayor del rey Gonzalo Martínez de Oviedo. En Calatrava el maestre Juan Núñez de Prado era próximo a los Guzmán.

Lo mismo ocurría con la orden de Santiago, pues al morir en 1338 su maestre Vasco Rodríguez, el rey "requirió que no eligiessen Maestre sin su parecer y licencia". A pesar de ello, los freires eligieron al sobrino del anterior, Vasco López, como maestre; este fue depuesto y huía a Portugal. Aunque el monarca quería nombrar a su hijo Fadrique, finalmente designó a Alonso Méndez de Guzmán ${ }^{43}$. Este moriría en el cerco de Algeciras, por lo que el rey nombró a su hijo Fadrique; al ser menor de edad, el gobernador de la orden fue el comendador mayor de León Fernando Rodríguez Mexia ${ }^{44}$.

En la primera mitad de este siglo, Alfonso XI intentó someter a la orden del Hospital, iniciada en 1328 en el enfrentamiento entre el prior Valbuena y el conde Alvar Osorio, seguido por el nombramiento por el Gran maestre como prior de Alfonso Ortiz de Calderón al que el rey, por su experiencia en Rodas, nombró almirante de la flota castellana días antes de la batalla del Salado. Más tarde, serían los propios freires quienes lucharían entre sí por el control de la orden y el cargo de maestre, si bien que la monarquía impondría su dominio, con la designación de Gutierre Gómez de Toledo

\footnotetext{
40 Rodríguez-Picavea, "Caballeros calatravos y linajes castellanos”, pp. 161-167.

41 Rades, Crónica de las tres Órdenes, Alcántara, f. 16r. Podríamos considerar como un precedente la Hermandad que en 1224 habían suscrito los maestres de Santiago y Calatrava, el prior del Hospital y el maestre provincial del Temple.

42 NovoA, "Los maestres de la orden de Alcántara", p. 319.

43 Rades, Crónica de las tres Órdenes, Santiago, ff. 42v-43v.

44 López Fernández, "Los Mexia en la encomienda mayor de León”, p. 148.
} 
en 1358, frente al castellán de Amposta, elegido por Inocencio VI; durante un tiempo coexistirían dos priores en Castilla. El siglo se acabaría con otros conflictos internos, hasta la elección de Rodrigo Gómez de Cervantes, en 1394. Pero, ese dominio sería diferente al ejercido sobre las otras órdenes castellanas ${ }^{45}$.

A la muerte de Alfonso XI en 1350, las órdenes estuvieron divididas en cuanto a los apoyos al rey Pedro o a Enrique de Trastámara y sus hermanos. Pedro I promovería, por ello, una serie de movimientos por ejecuciones o desposesiones en las dignidades, al interpretar fidelidades o traiciones. Calatrava, Santiago y Alcántara cambiaron de titulares por la voluntad del rey, con elecciones irregulares, que sólo sirvieron para dividirlas aún más. Así, Fadrique maestre de Santiago, sería desposeído del maestrazgo en 1354 y elegido maestre irregularmente, el comendador mayor Juan García de Villágera, hermano de María de Padilla, que moriría a finales de 1358 en un combate con el comendador mayor Gonzalo Mexia en Alarcón ${ }^{46}$. En cambio, la orden del Hospital de San Juan parecía no estar sujeta a esos vaivenes, pues en 1350 seguía como prior Alfonso Ortiz de Calderón, sustituido por Ferrán Pérez de Deza.

El maestre de Calatrava, Juan Núñez de Pardo sería desposeído del maestrazgo en 1353 y ejecutado en 1354. El monarca pedía la elección de Diego García de Padilla, hermano de María de Padilla, no aceptado por los freires. Se consumaba la disidencia del sobrino del maestre asesinado y comendador mayor de la orden, Pedro Estébañez Carpintero, quien se hizo nombrar maestre; sería derrotado en 1358 por los ejércitos del rey y de Diego García de Padilla. Quedaba la orden de Alcántara, en la que el maestre Ponce de León tendría una actitud vacilante, pero a menudo opuesta al rey, lo contrario que su clavero Suero Martínez. El maestre moriría en el verano de 1355; el rey se apresuraba a nombrar como maestre a Diego Gutiérrez de Ceballos, aunque a finales de año, el clavero sería el nuevo maestre ${ }^{47}$.

En 1358 moría en Sevilla el maestre Fadrique por mandato del monarca. En ese año, Pedro I pidió a los freires del Hospital que eligiesen como prior a Gutierre Gómez de Toledo, como así se hizo, en oposición al castellán Juan Fernández de Heredia, que había sido elegido prior de Castilla en 1356 por Inocencio VI ${ }^{48}$. Al morir en septiembre de 1359 el comendador mayor de León de la orden de Santiago Gome Suárez de Figueroa en la batalla del campo de Araviana, el rey hizo maestre de Santiago a García Álvarez de Toledo ${ }^{49}$. En menos de diez años, cambiaba por segunda vez la cúpula de las órdenes.

El prior del Hospital Gutierre de Toledo sería nombrado adelantado mayor del reino de Murcia y participaría en la guerra de los dos Pedros, ya como maestre de Alcántara, en la toma de Murviedro en 1362; en enero de 1365 moriría, al ir a aprovisionar ese

\footnotetext{
45 Barquero, "Disputas por el priorato del Hospital en Castilla", pp. 540-541 y 545-546.

46 Rades, Crónica de las tres Órdenes, Santiago, ff. 46r-v.

47 Rades, Crónica de las tres Órdenes, Alcántara, f. 27v.

48 López de Ayala, Crónica del rey D. Pedro, tomo I, año IX, 1358, cap. VIII, p. 278.

49 Rades, Crónica de las tres Órdenes, Santiago, f. 50r.
} 
castillo $^{50}$. El rey elegiría a Martín López de Córdoba, que no era freire, como nuevo maestre de Alcántara, lo que levantó protestas de los freires de la Orden, al tiempo que Pedro Muñiz de Godoy lo era por Enrique de Trastámara en 1366.

Hubo momentos en que no sólo hubo dos maestres de las órdenes, sino que se hacían transferencias entre ellas. Así, desde 1358 habría dos priores del Hospital: Gutierre Gómez de Toledo y el castellán de Amposta, Juan Fernández de Heredia. Lo mismo ocurría en 1359 con los maestres de Santiago: García Álvarez de Toledo, y Gonzalo Mejía; Calatrava en 1354-1358: Diego García de Padilla y Pedro Estébanez Carpentero, reemplazados por Martín López de Córdoba y Pedro Muñiz de Godoy desde 1367. Alcántara en 1365-1367 con Martín López de Córdoba y Pedro Muñiz de Godoy, sustituidos por Pedro Alfonso de Sotomayor.

Con la guerra civil castellana y la proclamación en 1366 en Calahorra y Burgos como rey de Enrique II, el maestre de Calatrava Diego García de Padilla se pasaría a su bando. El pretendiente llegó a un acuerdo con el maestre de Santiago, García Álvarez de Toledo para que renunciara al maestrazgo, en beneficio de Gonzalo Mejía, elegido por Enrique ${ }^{51}$. Después de la batalla de Montiel y la muerte de Pedro I, en marzo de 1369, Enrique II ordenó la captura de Martín de Córdoba en Carmona y su ejecución en Sevilla; fue sustituido en el maestrazgo de Alcántara por Pedro Muñiz de Godoy, que ya era desde 1365 maestre de Calatrava por designación del Trastámara ${ }^{52}$.

Esos nombramientos de los maestres por los monarcas castellanos no siempre transcurrieron en armonía, sino que, a menudo, los freires se mostraron reacios a su aceptación. Es lo que se deduce de la cita de los autores de la primera historia de la orden de Santiago:

Pero es mucho admirar, a los que este estado de maestre, alcançar desean, que deven entrar por la puerta de la orden, con elección justa i canónicamente fecha, porque este señor maestre -se refieren don Álvaro de Luna-i el dicho señor Ynfante -hablan del infante don Enrique de Aragón-, i don Juan García de Padilla, i el Ynfante don Fadrique, hermano del Rey don Pedro, i don Gomez Suarez de Figueroa, que dicho avemos, i don Martin Barragan, i don Alonso Mendez, sus antecesores, que ovieron la dignidad maestral con mano i favor de los Reyes, fuera de la voluntad y libertad de la orden, todos murieron a fierro, i ovieron los dichos fines ${ }^{53}$.

En 1384, Juan I consiguió una importante concesión del papa Clemente VII: el privilegio de nombrar directamente a los maestres de las órdenes militares castellanas de Santiago,

\footnotetext{
50 López de Ayala, Crónica del rey D. Pedro, tomo II, año XI, 1360, cap. XII, p. 17 y 29; Zurita, Anales, lib. IX, cap. LIX, p. 530.

51 Rades, Crónica de las tres Órdenes, Santiago, f. 50r-v.

52 Torres, Crónica de Alcántara, vol. I, f. 120.

53 Orozco; Parra, [Primera] Historia de la Orden de Santiago, Manuscrito de la RAH, Badajoz, Diputación de Badajoz, 1978, p. 375.
} 
Calatrava y Alcántara, en el caso de fallecimiento de sus titulares durante su reinado ${ }^{54}$. Era una vez más la expresión de la interferencia de los monarcas en la organización y funcionamiento de las órdenes. Pero no podían pretender hacer lo mismo con las órdenes internacionales como el Hospital, aunque lograban reivindicar un derecho de injerencia en las encomiendas situadas en sus reinos.

\section{Las incursiones y la guerra de fronteras luso-castellanas en la primera mitad del siglo XIV}

¿Qué podemos resaltar en este periodo de las actividades de las órdenes militares portuguesas? En el inicio del reinado de Afonso IV en 1325, la orden de Avis, con su maestre Gonçalo Vaz/Vasco Afonso se enfrentó a las tropas del medio hermano del rey, Afonso Sanches, que había invadido las regiones de Tras os Montes y Alentejo. Entraba con las tropas del rey en Alburquerque, a finales de 1325, en los dominios castellanos del infante portugués, después de que este le derrotara en Ouguela, de donde el maestre era frontero ${ }^{55}$. La orden de Alcántara apoyaba al infante ${ }^{56}$.

Castilla estuvo en guerra con Portugal desde los conflictos de Alfonso XI con su suegro Afonso IV, entre 1336 y 1338, provocada por la situación de abandono de la reina María por parte de rey castellano y por las luchas surgidas por la alianza matrimonial del infante heredero portugués Pedro con Constanza Manuel, enlace concertado como parte de una gran coalición de la aristocracia castellana, apoyada por el rey luso ${ }^{57}$. El ámbito de estos combates será la frontera entre los dos reinos, espacio concreto del desarrollo de las contiendas.

La guerra se iniciaría en el verano de 1336, con la invasión de Galicia por el ejército portugués del hermano del rey, Pedro Afonso conde de Barcelos $^{58}$. Un tiempo después, Afonso IV, que había solicitado de los alcaldes fronterizos con Castilla, entre ellos a Estevão Gonçalves maestre de Cristo, que le entregasen sus fortalezas, cercó Badajoz y arrasó su alfoz "e grande parte da terra que a Ordem de Santiaguo aly tem reçebeo muy grande dapno"s9.

El asedio se levantaría "no por la dificultad de asaltar la ciudad, tal y como nos informa la crónica del citado monarca, sino a causa de la llegada de las huestes de la orden de Alcántara, de las de los ricos-hombres andaluces y varias milicias concejiles" ${ }^{\circ}$. Rades

\footnotetext{
54 SuÁrez, Castilla, el Cisma y la crisis conciliar, p. 16. El texto de la bula pontifical en pp.163-165.

55 Pina, Chronica d'El-Rei Dom Afonso o Quarto, pp. 2-3; Martins M; Monteiro, "Portugal. II. The Late Middle Ages", p. 218.

56 Rades, Crónica de las tres Órdenes, Alcántara, ff. 16r-v.

57 Pina, Chronica d'El-Rei Dom Afonso o Quarto, pp. 126-127; NovoA, "Los maestres de la orden de Alcántara", p. 321.

58 Oliveira; Monteiro, Historia medieval de Portugal, p. 139.

59 Gran Crónica, cap. CXCIII, p. 156; Crónica de Portugal de 1419, pp. 250-251; MonTeIRo, "O armamento militar portugués", p. 103.

60 Torres, Crónica de Alcántara, vol. II, f. 4.
} 
nos habla de que el rey decía del maestre alcantarino Ruy Pérez de Maldonado, "ni le hauia seruido como era obligado"; lo mismo dice Torres, que "no le falta escusa, que como su Orden tenía en el Reyno de Portugal dos Encomiendas con muchos Lugares y bienes, y se hallaban favorecidos de su Rey, no quiso llegar a rompimiento con el y sus gentes"61. El maestre había mantenido una actitud equívoca en el conflicto.

La respuesta castellana fue una operación de castigo, que se extendió contra las poblaciones de Elvas y su término, Aronches y Olivenza, en la que se enfrentaron las órdenes de Avis y de Alcántara ${ }^{62}$. Un ejército castellano mandado por Fernando de Castro entró por el Miño y avanzó hasta cerca de Oporto, en donde se enfrentó a las huestes del arzobispo de la ciudad y al maestre de Cristo, Estêvão Leitão ${ }^{63}$.

La victoria del almirante Jofre Tenorio sobre una flota portuguesa en julio de 1377 y las reacciones consecuentes, llevó a la radicalización del conflicto, en el que las tropas castellanas con la orden de Alcántara y su maestre Gonzalo Martínez de Oviedo penetraron en el Algarve y cercaron Castro Marín, defendido por caballeros de Cristo. Llegaron hasta Tavira, antes de volver a Castilla, aunque siguieron las algaradas en Galicia y ataques a Lisboa, a pesar de una tregua de un año ${ }^{64}$. Anotamos, antes y después del Salado, los litigios que las órdenes de Avis y de Santiago tenían con ciertos concejos de algunos lugares y villas de sus señoríos, en 1336 y 1345, que podríamos suponer como el reflejo de la actitud de Afonso IV para controlar las órdenes ${ }^{65}$.

A partir de entonces los dos reinos y en particular sus órdenes militares se enfrentarán en episodios de guerra de desgaste o de frontera, hasta la intervención por un lado del legado papal Bernardo de Alba, obispo de Rodez, junto con el obispo de Braga y el maestre de Alcántara Gonzalo de Oviedo y, por otro, de la reina María, esposa de Alfonso XI, para establecer treguas y después la paz ${ }^{66}$. Gracias a estas mediaciones, se lograrían superar las diferencias y se definiría la ayuda que Afonso IV daría a su yerno para atacar a los meriníes en la batalla del Salado, en octubre de 1340 y el fin del apoyo portugués a los nobles rebeldes en Castilla ${ }^{67}$.

¿Eran legítimos los enfrentamientos bélicos de las órdenes militares con otros cristianos $\mathrm{y}$, sobre todo, con otras órdenes? Las castellanas no tuvieron ninguna duda en apoyar al rey de Castilla en las guerras contra Portugal e invadir el territorio luso, ni las portuguesas el territorio castellano. El capítulo general de Aviñón de 1367 estableció la prohibición hecha a los freires del Hospital de enfrentarse con las armas a otros cristianos, excepto para defender la orden, a su soberano o a la cosa pública ${ }^{68}$. Otro estatuto

\footnotetext{
${ }_{61}$ Rades, Crónica de las tres Órdenes, Alcántara, vol. II, f. 18r; TORRES, Crónica de Alcántara, vol. II, f. 5.

62 Cosme, "O reflexo das rivalidades luso-castelhanas", p. 390.

63 Oliveira; Monteiro, Historia medieval de Portugal, p. 140.

64 Pina, Chronica d'El-Rei Dom Afonso o Quarto, pp. 38-40; Rades, Crónica de las tres Órdenes, Alcántara, f. $19 \mathrm{v}$.

65 Marques, "O Conselho alentejano de Figueira e a ordem de Avis", p. 103.

66 Corral, "La orden de Alcántara durante la Edad Media", p. 25.

67 Gran Crónica, vol. II, pp. 320-323 y 362-363.

68 Delaville, Les hospitaliers à Rhodes, p. 163.
} 
prohibía a los hospitalarios, y quizás a las otras órdenes, hacer congregacions, conseils ne sacrements d'aliance ou d'emprise ne dommaige à la manière d'Espagne ${ }^{69}$, alusión a la intervención de las órdenes militares en la guerra civil castellana, contemporánea del capítulo. Estaba justificado acudir en defensa del rey amenazado, pero no se podía intervenir en otros episodios militares.

En octubre de 1340 se produjo la batalla campal del río Salado, que se inscribió dentro del espíritu de resurgimiento del ideal de cruzada propio de la Europa del Trescientos. En ella lucharon juntas las órdenes militares de los dos reinos al completo, en lo que fue un hecho excepcional y digno de resaltar. La bibliografía de esta batalla es muy completa, por lo que no nos detendremos en detallarla ni en analizarla. Sólo enumerar que en ella estaban las órdenes castellanas de Calatrava con su maestre Juan Núñez de Prado al frente, de Alcántara con Nuño Chamizo y de Santiago con Alonso Méndez de Guzmán; el maestre del Hospital Juan Alfonso Ortiz Calderón comandaba la flota castellana ${ }^{70}$. Por parte portuguesa, el rey Afonso IV se hizo acompañar por las órdenes militares portuguesas, la del Hospital de San Juan, con su prior Álvaro Gonçalves Pereira, la de Santiago con su maestre Gil Gonçalves Carvalho, la de Avis con Estêvão Gonçalves Leitão y la de Cristo con Gonçalo Vasques Coutinho. Aunque autores portugueses citan como maestre de Santiago a García Peres Escacho -aunque muere en 1327-, de Avis a Gonçalo Vasques o Vaz y de Cristo a Estêvão Gonçalves Leitão ${ }^{71}$.

Esta victoria tuvo una gran repercusión en toda la cristiandad, reflejada más tarde en la embajada enviada por Alfonso XI al papa Benedicto XII, con gran alarde de regalos, joyas, tejidos y prisioneros musulmanes, así como el pendón del rey en el Salado y veinticuatro pendones musulmanes, como parte del botín recogido en el alfaneque de los meriníes ${ }^{72}$. Esta embajada fue un elemento de la propaganda que la monarquía castellana quería proyectar como discurso político, puesto que Alfonso XI había sido excomulgado. Se intentaba de ese modo justificar que el monarca "era un rey noble y destacado católico, que honraba mucho a la Iglesia, y cuya actuación estaba presidida por el temor a Dios". Sin embargo, el cronista no puede dejar de anotar que el objetivo último de la embajada era la petición al papa de nuevas ayudas para proseguir la guerra contra el Islam ${ }^{73}$.

Así mismo, Afonso IV envió al pontífice las banderas tomadas del Salado, preparando el camino al reconocimiento de la legitimidad de su cruzada al otro lado del Estrecho. Benedicto XII emitiría en 1341 la bula Gaudeamus et exultamus, con las mismas indulgencias que las otorgadas para Tierra Santa ${ }^{74}$.

La continuación del Salado sería la campaña contra Algeciras entre 1342 y 1344, cuando aún persistían las buenas intenciones de colaboración de los dos reinos; el papa

\footnotetext{
Josserand, Eglise et pouvoir dans la Péninsule Ibérique, p. 566.

López Fernández, "Las órdenes religioso-militares en las fronteras de Tarifa", p. 63.

Martins M, “As hostes das ordens militares em Portugal”, p. 322.

2 Gran Crónica, cap. CCCXXXIV, pp. 445-447.

73 Rodríguez-Picavea, "Diplomacia, Propaganda y Guerra Santa", p. 768.

74 García Fernández, "Las relaciones internacionales", p. 214.
} 
Clemente VI promulgó la Cruzada en 1343. En el cerco estuvieron presentes las tres órdenes castellanas con sus maestres y la del Hospital, aunque su prior Alonso Ortiz fue enviado a Aviñón para recabar un préstamo para dicha empresa. En esa campaña morirían tres maestres de las órdenes. No hay constancia de ayudas portuguesas, pero sí la presencia de nobles lusos en 1344. Sólo faltaba ahora tomar Gibraltar, con la presencia de las órdenes militares castellanas; se solicitó otra vez la ayuda de Portugal -"muytas galles \& de Portugal lhe forão dez bem armadas, \& con ellas o ditto Almirante Carlos Paçanha" ${ }^{5}$, , pero Alfonso XI murió por la peste negra a finales de marzo de $1350 \mathrm{y}$ se interrumpió la campaña.

\section{Guerras civiles en Portugal (1355-1356) y en Castilla (1356-1369)}

Afonso IV parece ser que procuró tener una buena relación con Castilla, lo que estaría en la base del conflicto que le iba a oponer a su heredero el infante Pedro, en el episodio bien conocido de Inés de Castro ${ }^{76}$. Después del asesinato de Inés, Pedro se enfrentó a su padre en una guerra civil, en 1355-1356; en ella se cercó Porto, que resistiría al mando del prior del Hospital, Álvaro Gonçalves Pereira, así como del maestre de Cristo, Rodrigo Eanes $^{77}$. A la muerte del rey Afonso, sería elegido maestre de Cristo, por renuncia del maestre Eanes, Nuno Rodrigues Freire de Andrade, de linaje castellano ${ }^{78}$, que tutorizará al hijo bastardo del rey Pedro I, João, futuro maestre de Avis. Se iniciaba ahora una serie de emigraciones de exilados portugueses que se prolongaría hasta el siglo XV.

Entre 1356 y 1365 la guerra de los Dos Pedros desviaría la atención del monarca castellano hacia Aragón, en sus enfrentamientos con Pedro IV (1336-1387) y su hermano Enrique de Trastámara, que continuaría con la confrontación fratricida en la guerra civil castellana, desde la proclamación de Enrique como rey de Castilla en Burgos en 1366, hasta marzo de 1369. Las órdenes militares castellanas estuvieron divididas en cuanto a los apoyos al rey Pedro o a Enrique y sus hermanos, como se vería en las batallas de Nájera, en 1360 y 136779, al contrario de lo acaecido en la guerra contra Aragón, en la que apoyaron a su monarca. Enrique II nombraría en 1366, maestres de Santiago a Gonzalo Mejía y de Calatrava a Pedro Muñiz Godoy, los dos refugiados en Aragón; Garcia Álvarez de Toledo recibiría en compensación un señorío, que sería el origen de la casa de Alba ${ }^{80}$.

Con Pedro I de Portugal se tuvo una decena de años de paz, en la que las relaciones con su sobrino Pedro I de Castilla, fueron cordiales y de colaboración ${ }^{81}$. El rey portugués

\footnotetext{
75 PINA, Chronica d'El-Rei Dom Afonso o Quarto, p. 182.

76 Ibidem, pp. 71-72; Oliveira; Monteiro, Historia medieval de Portugal, p. 143.

77 Martins M; Monteiro, "Portugal. II. The Late Middle Ages", p. 222.

78 Costa P, “As adaptações das Ordens Militares”, p. 149, notas 25 y 27.

79 Rades, Crónica de las tres Órdenes, Calatrava, f. 58; ZURITA, Anales, lib. IX, cap. XXVIII, pp. 393-396.

80 López de Ayala, Crónica del Rey D. Pedro, p. 541.

81 García Fitz, "Nuevos desencuentros", p. 51.
} 
auxilió a su sobrino, en 1359, con diez galeras, en la guerra de los Dos Pedros, en la campaña sobre Barcelona e Ibiza, donde estuvo el prior del Hospital Gutierre Gómez de Toledo. Ese apoyo se renovaría, en 1361 con el envío de seiscientas lanzas, mandadas por el maestre de Avis Martim de Avelar, en 1363 con trescientos caballeros al mando del maestre de Santiago portugués, Gil Fernandes de Carvalho y en 1364, con diez galeras, al mando del almirante Pesaña ${ }^{82}$.

El 14 de marzo de 1369 tuvo lugar en Montiel el último choque de la guerra fratricida de Castilla, con la derrota de Pedro I. El desenlace del conflicto se desarrollaría en la noche del 22 al 23 de marzo de 1369, en la que Enrique daba muerte a su hermanastro. La guerra civil había concluido.

La subida al trono de Enrique II supuso un cambio importante en cuanto a las alianzas en el marco del Guerra de los Cien Años. Francia ya había apoyado al candidato Trastámara e Inglaterra a los petristas, lo que significó la ayuda a Fernando I de Portugal en sus aspiraciones y finalizó con la intervención del duque de Lancaster en territorios castellanos. Se pasó pues a una fase de internacionalización de los conflictos.

\section{Las guerras fernandinas. Una nueva dinastía en Castilla}

El reinado de Fernando I, último rey de la primera dinastía portuguesa, fue muy complejo, con dificultades políticas, económicas y demográficas, debidas a la crisis del siglo XIV, a la Guerra de los Cien Años y al Cisma de Occidente, iniciado en 1378 en su sede aviñonesa ${ }^{83}$. Fernando I tenía varios hermanastros, fruto de las relaciones de su padre con Inés de Castro, por un lado, y por otro con Teresa Lourenço, João, designado maestre de la orden de Avis con sólo seis o siete años, en $1364^{84}$.

Ya en marzo de 1367, el rey portugués recibió a los embajadores de Enrique II de Castilla y de Pedro IV de Aragón, con objetivos de paz, acogidos favorablemente. Estaban presentes, Álvaro Gonçalves Pereira, prior del Hospital en Portugal y Nuno Rodrigues Freire de Andrade, maestre de la orden de Cristo. Objetivos de paz que pronto se tornarían en la dirección contraria, pues la muerte en 1369 en Montiel de Pedro I y la ascensión al trono de Enrique II, propiciaría que Fernando recibiera consejos de iniciar la lucha contra el monarca castellano, al ser biznieto legítimo de Sancho IV de Castilla (1284-1295) ${ }^{85}$. Enrique II se emplearía a fondo en eliminar los focos petristas, al tiempo que intentaría romper la prevista alianza anti-castellana de los otros reyes peninsulares y del rey de Granada.

Melén Suárez sería elegido maestre de Alcántara en 1369, al ser depuesto y encarcelado Martín de Córdoba. El maestre daría su apoyo a Fernando I de Portugal después de

\footnotetext{
82 Oliveira; Monteiro, Historia medieval de Portugal, p. 151.

83 IBIDEM, pp. 153-154.

84 Fernandes; Oliveira, "Las Órdenes Militares", p. 144; Martins M; Monteiro, "Portugal. II. The Late Middle Ages", p. 222.

85 IBIDEM, p. 155.
} 
Montiel, lo que dividió a la orden; su actitud resulta curiosa, pues estaba en el bando de Enrique en la batalla de Nájera, donde fue hecho prisionero por Pedro I, quien le había nombrado maestre. ¿Qué le hizo cambiar de posición? Por el enfrentamiento entre el clavero Diego Martínez y el maestre, este tuvo que huir a Portugal, donde, según la Crónica de Alcántara, Fernando I le puso como frontero y "le prometio el Maestrazgo de Calatrava. Otros quieren decir (que) le dio de hecho el de Avis" "86, aunque no figura en la relación de sus maestres. El siguiente maestre de Alcántara fue Ruy Díaz de la Vega en 1370, comendador mayor y embajador en Aragón, elegido por la voluntad de Enrique II.

El rey luso, para consolidar sus posesiones en Galicia, la invadió en julio de 1369; además, "en abril de 1370 el prior de la orden del Hospital hacía una entrada por Badajoz" $"$. Enrique II reaccionó rápidamente, fue a Zamora en julio y, con la ayuda de las compañías blancas de Bertrand du Guesclin, llegaba hasta Santiago y penetraba en el norte de Portugal, en agosto, atacando Porto, Braga y Guimarães, en septiembre. Mientras, los maestres de Calatrava y de Santiago controlaban la frontera portuguesa y seguían el asedio a Zamora. El rey de Portugal abandonaba La Coruña, dejando tropas al mando del maestre de Cristo, Nuno Rodrigues Freire. Cuando Granada atacó Algeciras, Enrique II abandonaba las regiones norteñas, dirigiéndose a Castilla, en octubre. Había logrado paralizar las campañas portuguesas ${ }^{88}$.

El rey de Castilla retomaría las operaciones a primeros de 1370. Mientras, en junio, Bertrand du Guesclin y las compañías blancas abandonaban el suelo castellano, al volver a Francia. Los maestres de Santiago Gonzalo Mejía y de Alcántara Pedro Muñiz, habían establecido en junio treguas con el rey de Granada, por ocho años, lo que permitió a Enrique II dedicar toda su energía a los litigios con Portugal ${ }^{89}$. Enrique II emprendió el asedio de Ciudad Rodrigo, en el verano y recuperaba Zamora en febrero de 1371. Fernando I, aunque intentó reactivar el tratado con Aragón, comprendió que era mejor retomar la situación y ordenó al conde de Barcelos firmar un tratado de paz con Castilla, en marzo de 1371, en Alcoutim, por la mediación de los legados de Gregorio $\mathrm{IX}^{90}$. Se devolvieron territorios y castillos ocupados -los portugueses quedaron bajo el mando del prior del Hospital Álvaro Gonçalves-y se asumieron otras medidas, como compromisos matrimoniales entre Fernando I y la hija de Enrique II, Leonor de Castilla. En mayo se tomó Carmona, después de dos meses de asedio y se ejecutó a Martín López de Córdoba; intervino en las negociaciones de rendición y captura el nuevo maestre de Santiago Fernando Osórez ${ }^{91}$. Sólo quedaba como reducto petrista Galicia. El maestre de Alcántara Ruy Díaz de la Vega asistió a las Cortes de Toro, en septiembre y haría

\footnotetext{
6 Rades, Crónica de las tres órdenes, Alcántara, ff. 30v-31r.; Torres, Crónica de Alcántara, ff. 127-129.

7 Montaña, "E Levaram Captivos", pp. 15-16.

88 Valdeón, Enrique II, p. 104; Monteiro, "Arcaísmo o modernidade no Exército Português", p. 262;

Oliveira; Monteiro, Historia medieval de Portugal, p. 156.

89 VALDEÓn, Enrique II, pp. 106-108.

90 García Fitz, "Nuevos desencuentros", pp. 55-56.

91 VAldeÓn, Enrique II, p. 110.
} 
frente a la entrada de tropas portuguesas contra Alcántara, mandadas por Lourenço da Cunha, señor de Morgado, por lo que tuvieron que regresar a sus tierras ${ }^{92}$.

Fernando I decidió volverse hacia Inglaterra y procuró atraerse a la nobleza. Por ello, en 1372, contrajo matrimonio con Leonor Téllez de Meneses, casada con Lourenço da Cunha y sobrina del conde de Barcelos, rompiendo el compromiso con Leonor de Castilla $^{93}$. En Inglaterra, en donde había refugiados petristas, se celebraron las bodas de las dos hijas de Pedro I de Castilla con los hijos de Eduardo III de Inglaterra, Juan de Gante duque de Lancáster y su hermano Edmundo conde de Cambridge.

El rey de Castilla, para afianzar el poder real se rodeó de una nueva nobleza, que sería de su total confianza, frente a los parientes del rey y a la antigua nobleza, diezmada en la guerra civil. Sería una nobleza al servicio del rey. Igualmente, procuraría que al frente de las órdenes militares estuviesen maestres fieles a su persona: Santiago con Gonzalo Mejía y desde agosto de 1370 con su sobrino Fernán Osórez; Calatrava con Pedro Muñiz; Alcántara con Melén Suárez hasta su paso al bando de Fernando I, sustituido por Ruy Díaz de la Vega; el Hospital de San Juan con su prior, Lope Sánchez de Somoza. En julio de 1372 se firmó el tratado de Talgide, por el que Fernando I renunciaba a sus pretensiones sobre Castilla dejando el camino libre a Juan de Gante, en defensa de las reivindicaciones de su esposa Constanza a cambio de ayuda militar inglesa ${ }^{94}$. El rey luso "confíaba tomar la jurisdicción y defensa de Tomar, Pombal, Loure y otras villas a la orden de Cristo como medida preventiva ante una posible ofensiva castellana" $"$.

A mediados de diciembre de 1372, Enrique II invadió Portugal, por la Beira, mientras las órdenes de Santiago y de Alcántara lo hacían desde Alcántara, para unirse al rey en Coimbra y lanzarse sobre Lisboa, en la segunda "guerra fernandina". La orden de Santiago se enfrentaría a su homónima portuguesa, por lo que tuvieron que pedir la absolución al pontífice por la excomunión a la que habían incurrido, al matar a tres freires portugueses $^{96}$. Fernando I solicitó ayuda a Inglaterra, según los acuerdos de Talgide.

Las tropas inglesas no llegaban nunca, por lo que, cuando Enrique II puso cerco a Lisboa, en febrero de 1373, con los maestres de Santiago y de Calatrava y el conde de Niebla e incendió una parte de la ciudad, don Fernando aceptó negociar la paz. Se acordó el 19 de marzo en Santarém, en condiciones difíciles: alianza con Castilla y Francia contra Inglaterra, expulsión de los petristas y perdón a ciertos personajes y enlaces matrimoniales, uno de ellos el de la infanta Beatriz, recién nacida de su enlace con Leonor Téllez de Meneses y otros infantes. Para "sellar la reconciliación se celebró una fiesta en unas barcas sobre el Tajo ${ }^{97}$.

\footnotetext{
Rades, Crónica de las tres órdenes, Alcántara, f. 31r.; Torres, Crónica de_Alcántara, vol. II, f. 132. IBIDEM, f. 133.

Oliveira; Monteiro, Historia medieval de Portugal, p. 160.

5 Antt, $C E$, Caixa 31, no 18, cit. SÁnChez SesA, "Cisma, religión y propaganda”, p. 455.

6 Rades, Crónica de las tres órdenes, Santiago, f. 52r.

97 Oliveira; Monteiro, Historia medieval de Portugal, pp. 161-162; Valdeón, Enrique II, pp. 142-143.
} 
En 1375 se eligió maestre de Alcántara a Diego Martínez, comendador mayor, que se enfrentó a tropas lusas que habían tomado Valencia de Alcántara, sin poderla recuperar, ni siquiera después de "los conciertos y capitulación de las pazes que se asentaron éntre los Reyes de Castilla y Portogal"98. En 1376 se abordaban, según la paz de Santarem, los enlaces entre infantes portugueses y castellanos, sin éxito.

La muerte de Enrique II en mayo de 1379 y la subida al trono de Juan I hizo que Fernando I pensase en aprovechar ese momento de inestabilidad política para avanzar en el doble juego con Castilla e Inglaterra. Siguieron adelante otros proyectos matrimoniales de Fernando I para su hija Beatriz, ahora con Enrique, heredero de Juan I, al tiempo que se reactivaba la alianza con los ingleses - tratado de Estremoz en julio de 1380-99. Pensaba en esa tan hablada y planeada invasión de Castilla, ahora con el conde de Cambridge, con cuyo hijo prometía casar ahora a Beatriz. El tratado de Santarem se relegaba al olvido.

El infante Martín de Aragón, por su amistad con Juan I de Castilla, proyectaba participar en una nueva guerra entre Castilla y Portugal en 1380, pero renunciaría al proyecto por la oposición de Pedro IV en agosto de $1381^{100}$.

Los maestres de Santiago, Fernando Osórez y de Alcántara Diego Martínez, fronteros en Badajoz, tenían cercada Elvas, cuando en febrero de 1381 se les oponía João de Avis, que había sido enviado como frontero a Olivença. Juan I les mandaba en mayo reunirse con el infante Juan de Portugal en Badajoz y atacar el Alentejo; el infante vio en esos enfrentamientos la ocasión de iniciar una revuelta en Portugal, en donde decía tener partidarios. Se puso "bajo la bandera de Fernando Osórez maestre de Santiago, a quien se le había encargado la dirección de las operaciones en Extremadura". En junio el maestre de Santiago y el maestre de Alcántara entraban en tierras portuguesas, lo que precipitó la llegada de las tropas anglo-lusas en julio. Se cercó Elvas en julio-agosto, sin éxito; "en el campo contrario estaban nobles lusos, entre los que figuraba el hermano bastardo del rey, João, maestre de Avis". Se iniciaba así la "tercera guerra fernandina". Fuerte de una victoria naval en Saltes, Juan I atacó el interior de Portugal, en Tras-osMontes y la Beira hasta el Alentejo, con los maestres de Santiago y de Alcántara ${ }^{101}$.

El 19 de julio de 1381 llegaba a Lisboa la expedición del conde Edmundo de Cambridge, con cuarenta y ocho embarcaciones y tres mil combatientes. Desde agosto, Portugal pasaba de la obediencia a Aviñón a la de Urbano VI, por las presiones inglesas y se celebraba en septiembre el compromiso de Beatriz con el infante inglés Eduardo, hijo del conde, "pero no las bodas, porque ella tenía sólo ocho años de edad"102. Las tropas inglesas se instalaban en el Alentejo. En el inicio de 1382, se formaría en Portugal un bando partidario del infante Juan, en el que estaba ahora el maestre de Avis, enfrentado

\footnotetext{
8 Rades, Crónica de las tres órdenes, Alcántara, f. 32r.

99 SuÁreZ, Juan I, pp. 48 y 56-57.

100 Ferrer, "L'infant Martí i un projecte d'intervenció", pp. 205-233.

101 Torres, Crónica de Alcántara, vol. II, f. 145; SUÁREZ, Juan I, p. 74; Oliveira; Monteiro, Historia medieval de Portugal, p. 166.

102 SuÁrez, Juan I, p. 78.
} 
a la reina Leonor Téllez y su consejero Juan Fernández de Andeiro. En la primavera de ese año, se encarceló al maestre João de Avis, quizás por manifestar opiniones contrarias a la reina; debió su vida a la intervención del conde de Cambridge ${ }^{103}$.

En junio, Lisboa, bajo el mando del prior del Hospital Pedro Álvares Pereira nombrado ese año gobernador de la ciudad, resistió el ataque de una expedición naval castellana. Esa ofensiva provocó que las tropas luso-inglesas, mandadas por el conde de Cambridge y el maestre João de Avis, se dirigieran y pretendieran atacar las zonas fronterizas de Elvas-Badajoz, en julio con un ejército considerable: cinco mil hombres de armas, mil quinientos jinetes y muchos peones, aunque las fuentes lusas difieren en los efectivos: doscientos jinetes y el doble de arqueros. Arrasaron los castillos de Cortijo y de Lobón y provocaron la muerte o el encierro de sus defensores ${ }^{104}$. A finales de mes, al otro lado de la frontera, se encontraba el ejército de Juan I; las tropas se mantuvieron en sus territorios quince días frente a frente, prestas a combatir, lo que nunca ocurrió ${ }^{105}$.

Fernando I inició en agosto, sin avisar a sus aliados ingleses, negociaciones con los castellanos; la paz se firmaría en Elvas. La infanta Beatriz sería prometida a un segundón de Juan I, el infante Fernando, se devolverían las naves y los prisioneros retenidos en Huelva y Castilla y se repatriaría a los ingleses presentes en Portugal. El acuerdo estuvo a punto de frustrarse por la negativa de Juan I a aceptar ciertos puntos; lo resolvió Fernando Osórez ${ }^{106}$. A su vuelta a Lisboa, por la influencia del legado papal, el cardenal Pedro de Luna, el monarca puso el reino bajo la obediencia de Aviñón y, por el empeño del conde de Ourém y del obispo de Lisboa, se intentó firmar en Pinto, en diciembre de 1382, un tratado de paz. Se había propuesto a Juan I, en septiembre de 1382, al morir la reina de Castilla Leonor de Aragón, su enlace matrimonial con la infanta Beatriz de Portugal ${ }^{107}$. La infanta era otra vez moneda de cambio en todas las transacciones luso-anglo-castellanas.

El 3 de abril de 1383 se firmaba en Salvatierra de Magos las capitulaciones del enlace de Juan I y de Beatriz ${ }^{108}$. En el séquito de la infanta portuguesa se encontraban el maestre de Avís, João, el de Santiago, Fernando Afonso de Albuquerque, el de Cristo, Lope Dias y el prior del Hospital, Pedro Álvares Pereira. Entre los que juraron el cumplimiento por el rey de Castilla de lo acordado, estaban los maestres de Santiago, Pedro Fernández Cabeza de Vaca y de Alcántara, Diego Martínez ${ }^{109}$. Entre el 13 y el 17 de mayo se celebraron en Badajoz y Elvas las bodas del rey castellano y de la infanta Beatriz de Portugal, muy cerca de donde un año antes habían estado acampados los dos ejércitos. En los diferentes juramentos y pleitos homenajes figuraban los anteriores cuatro maestres portugueses y los dos castellanos; João de Avis parecía aceptar estos acuerdos. El

\footnotetext{
${ }^{103}$ IBIDEM, p. 80.

104 SuÁrez, Juan I, p. 81; Oliveira; Monteiro, Historia medieval de Portugal, p. 167.

105 Rodríguez Amaya, "Bodas de Juan I de Castilla”, pp. 75-77.

106 Lopes, Crónica do senhor rei dom Fernando, p. 429.

107 SuÁrez, Juan I, pp. 92-93.

108 IBIDEM, pp. 94-95; Oliveira; Monteiro, Historia medieval de Portugal, p. 168.

109 Rodríguez Amaya, “Bodas de Juan I”, pp. 85-92.
} 
pleito homenaje del día 21 se hizo en manos del maestre de Santiago. Fernando I envió a Inglaterra una misiva justificando su actitud.

El 22 de octubre de 1383 fallecía en Lisboa el rey Fernando I.

\section{Las guerras civiles y de sucesión portuguesas. Una nueva dinastía en Portugal}

Se iniciaba ahora un período de renovación dinástica, una etapa muy agitada de la historia política portuguesa, que desembocaría en la "revolución" de 1383-1385 y vería la aparición de la dinastía joanina o de Avis, que iba a pilotar la regeneración de la sociedad portuguesa al servicio de la política de la nueva monarquía. Culminaría con la proclamación del maestre de Avis como el rey João I de Portugal en las Cortes de Coímbra de abril de $1385^{110}$. Por si fuera poco, "a la guerra civil portuguesa entre partidarios y detractores del legitimismo de Beatriz, se sumó la guerra de independencia frente a Castilla, la enemistad franco-inglesa y el conflicto religioso por el Cisma" "11.

Después de la muerte de Fernando I, Juan I de Castilla planeó la subida al trono portugués de su esposa Beatriz y poner "el reino en su obediencia”. En octubre se constituía el consejo de Regencia portugués, con la reina Leonor como máxima autoridad, que despachaba los asuntos del reino. "El primero de los nobles portugueses que escribió a Juan I fue el maestre Joao de Avis, que le pedía que cuanto antes acudiera a Portugal, para hacer valer el derecho de Beatriz" ${ }_{112}$. Lo que se pretendía era impedir que la reina Leonor y su consejo se consolidasen en el poder, ya que la legitimidad la tenía Beatriz y sus futuros hijos. Juan I se nombraba rey de Portugal, reconocería a la regente y le pedía que proclamase a Beatriz como reina.

La presencia de tropas castellanas en Plasencia y la prisión del infante Juan llevaron a los portugueses a temer la invasión del reino y el apoyo a la regente; se confundía entonces a Juan I y a Leonor Téllez como del mismo bando. Los motines que se levantaron en Lisboa y Porto no auguraban nada bueno para Juan I, pues el sentimiento nacional portugués tenía un solo enemigo: Castilla. Juan I nombraría un consejo del reino en el que entraron las grandes familias lusas, entre las que estaba Pedro Álvares Pereira, prior del Hospital en Portugal ${ }^{113}$. Las órdenes militares lusas abrazaron la causa del maestre de Avis, excepto una parte del Hospital, que seguía al prior Pereira y otra de la orden de Avis, que seguiría al clavero, así como el canciller de la orden de Cristo, Gonçalo Tenreiro ${ }^{114}$. La evolución de los hechos de 1384-1386, es bien conocida y no vamos a entrar en detalles.

En la incursión en la que se llegó hasta Lisboa en febrero de 1384, en las tropas castellanas, con mil hombres de armas, estaban las órdenes militares: la de Santiago, con su

\footnotetext{
110 SuÁrez, Juan I, p. 150; Oliveira; Monteiro, Historia medieval de Portugal, p. 180.

111 Olivera, Pax in Bello, p. 57.

112 SuÁreZ, Juan I, p. 125.

113 IBIDEM, pp. 128-129 y 132.

114 Monteiro, A guerra em Portugal, p. 81; Silva, "A Ordem de Cristo”, p. 55.
} 
maestre Pedro Fernández Cabeza de Vaca, la de Calatrava con Pedro Muñiz de Godoy, la de Alcántara con Gonzalo Núñez de Guzmán y también parte de las portuguesas del Hospital con Pedro Álvares Pereira y de la de Cristo. En marzo se bloqueó Lisboa por mar, mientras el maestre de la orden lusa de Santiago, Fernando Afonso de Albuquerque era enviado a Inglaterra, para defender la causa de João de Avis y presentar al duque de Lancaster lo sucedido como su gran oportunidad para conseguir el trono castellano ${ }^{115}$. En mayo Juan I ponía cerco a Lisboa.

En 1384, Juan I nombraría frontero al nuevo maestre de Alcántara Diego Gómez Barroso, que se instalaría en Crato, sede del Hospital en Portugal, quien junto al conde de Niebla y al almirante Sánchez de Tovar se enfrentaría al condestable Nuno Álvares Pereira, entre Badajoz y la Albuhera, muriendo el maestre de Alcántara Diego Barroso ${ }^{116}$. En abril señalamos la victoria portuguesa en Atoleiros, de mayor importancia política y psicológica que militar. Se había recuperado Tomar y, en junio, el maestre de Cristo Lope Dias de Sousa, en ayuda ahora del maestre de Avis, tomaba Ourem, localidad procastellana, aunque sería hecho prisionero de los castellanos en Torres Novas y liberado después de Aljubarrota ${ }^{117}$.

A causa de una epidemia de peste, Juan I y su ejército se volvieron a Castilla en septiembre. En Lisboa habían muerto por esta razón no solo diversos nobles, sino también el maestre de Santiago Pedro Fernández Cabeza de Vaca y su sucesor, no elegido canónicamente, Rodrigo González Mejía y el elegido Fernando Alfonso de Valencia, siendo finalmente impuesto, por voluntad de Juan I, como maestre Pedro Muñiz de Godoy, que lo era de Calatrava ${ }^{118}$. Era el preludio de un baile de maestres de las órdenes. Será elegido maestre de Calatrava Pedro Álvares Pereira, huido del reino vecino al perder el priorato del Hospital y que morirá en la batalla de Aljubarrota; se votaría después como su sucesor a Gonzalo Núñez de Guzmán, maestre de Alcántara y como maestre alcantarino a Martín Yáñez Barbudo, que había sido clavero de Avis.

En la primavera de 1385, João I, la orden de Avis y Nuno Álvarez Pereira se dedicarán a poner cerco y a tomar villas y territorios partidarios de Beatriz, cercanos a la frontera, tanto en el Miño como en el Alentejo ${ }^{119}$. Así mismo, en mayo, un ejército portugués derrotará en Trancoso a uno castellano que regresaba de una incursión sobre Viseu ${ }^{120}$. En abril-mayo de 1385, Juan I convocaba la movilización general de Castilla, para asegurar una entrada por Badajoz-Elvas. En julio, Juan I, al que se le habían unido numerosos nobles y las órdenes militares de Calatrava, Santiago y Alcántara, con sus maestres, Pedro Álvares Pereira, Pedro Muñiz de Godoy y Gonzalo Núñez de Guzmán,

\footnotetext{
115 SuÁrez, Juan I, pp. 133 y 135.

116 Rades, Crónica de las tres Órdenes, Alcántara, f. 32v.; Torres, Crónica de Alcántara, vol. II, f. 130.

117 SuÁrez, Juan I, p. 139; SILVA, “A Ordem de Cristo”, pp. 54-55.

118 Rades, Crónica de las tres Órdenes, Santiago, ff. 52v-53r; Calatrava, ff. 62r.; SuÁrez, Juan I, p. 141.

119 IBIDEM, p. 150.

120 IBIDEM, p. 156; Torres, Crónica de Alcántara, vol. II, ff. 153-154.
} 
así como el clavero de Avis Martín Yáñez de Barbudo y Fernando Dantes, caballero de la orden lusa de Santiago, penetraba en Portugal y llegaba hasta Lisboa, vía Coimbra ${ }^{121}$. En agosto de 1385 tendría lugar la batalla de Aljubarrota, con victoria portuguesa, en la que participarán las órdenes militares de los dos reinos.

Desde el otoño de 1385, el condestable Nuno Álvares Pereira efectuaría varias entradas en territorio castellano, por Mérida y Jerez de Badajoz, en la que se afrontó en la batalla de Valverde, a Juan Alonso de Guzmán, conde de Niebla y a otros caballeros, así como a las tres órdenes nacionales castellanas, Calatrava con Gonzalo Núñez de Guzmán, Alcántara con Martín Yáñez de Barbudo, con trescientas lanzas y Santiago con Pedro Muñiz de Godoy, que murió en ese enfrentamiento ${ }^{122}$. En 1386 entraba por Ciudad Rodrigo y sitió Coria, sin éxito; los maestres de Santiago, García Fernández Mejía/de Villagarcía y de Alcántara, Martín Yáñez, cercaron y tomaron la villa portuguesa de Campo Maior, después de que este último recobrara Valencia de Alcántara ${ }^{123}$.

Con el inicio de la nueva dinastía, los maestres de las órdenes militares portuguesas verán recompensado su apoyo al antiguo maestre de Avis, al recibir mercedes y cargos en la corte. Era una manera de paliar la llamada crisis del siglo XIV, que vio las rentas de las tierras disminuir, hasta el punto de que los señoríos ya no eran suficientes para poder asegurar el mismo nivel social de sus titulares. Todos buscarán estar al servicio del rey, desde sus cargos cortesanos, políticos, militares o administrativos, como el maestre de Santiago Fernando Afonso de Abuquerque, que sería nombrado embajador en Inglaterra, para plasmar la ayuda al nuevo monarca. También habría nuevos nombramientos, como el del priorato del Hospital para Álvaro Gonçalves Camelo, en sustitución de Pedro Álvares Pereira y la de maestrazgo de Avis para Fernando Rodrigues ${ }^{124}$. Así, si ya Nuno Freire de Andrade, de la orden de Cristo, fue canciller mayor en 1367 y frontero en Coimbra en 1369, ahora Fernando Rodrigues de la orden de Avis sería frontero mayor en Lisboa, en 1385 y Álvaro Gonçalves Camelo prior del Hospital mariscal de las huestes del reino y merino mayor entre Duero y Miño y Tras-os-Montes y, en 1389, embajador del rey en las negociaciones de treguas con Castilla ${ }^{125}$. Lopo Dias de Sousa, maestre de Cristo, será mayordomo mayor de la reina Filipa de Lancaster.

Estos planteamientos no serán exclusivos de Portugal, sino la extensión de los que ya habían empezado a aparecer en Castilla y en la corona de Aragón, con la ascensión de la "nobleza nueva" o "nobleza cortesana" o aún "nobleza de toga" y que verán su culminación en el siglo $\mathrm{XV}^{126}$.

\footnotetext{
121 Torres, Crónica de Alcántara, vol. II, f. 154.

122 Rades, Crónica de las tres Órdenes, Santiago, f. 53r.; Oliveira; Monteiro, Historia medieval de Portugal, p. 192.

123 Rades, Crónica de las tres Órdenes, Alcántara, f. 33v.

124 Monteiro, A guerra em Portugal, pp. 81-82; VAsconcelos, "Nobreza e Ordens Militares", p. 59.

125 Costa P, “As adaptações das Ordens Militares”, p. 152, nota 43.

126 Moxó, "De la nobleza vieja a la nobleza nueva", pp. 1-210.
} 


\section{Intervención de Inglaterra}

En mayo de 1386 se firmaba al pacto de Windsor entre Inglaterra y Portugal. El objetivo del duque de Lancaster, casado con una hija de Pedro I de Castilla, era tomar el trono de Castilla, para lo que proyectaba una gran campaña militar. Así, en el verano Juan de Gante llegaba a Galicia.

En el Cisma Portugal, cambiaría una vez más de obediencia y pasaría de reconocer a Aviñón a hacerlo con Roma. Urbano VI en 1383, otorgó indulgencias a quien ayudara a Juan de Gante, le dio el título de cruzado y le reconoció como rey de Castilla. Recibía en octubre de 1387 una súplica que le dirigía el prior del convento de Avis, pidiendo "la confirmación como maestre de la orden de Fernão Rodrigues"127. La firma de la paz con Castilla no debió de modificar nada, pues Bonifacio IX, en enero de 1391 emitía una bula por la que facultaba como monarca a João I, a pesar de su condición de "Mestre de Aviz o adulterino, possa casar e ser rey"128.

Juan I se instalaba en Valladolid, desde donde intentaba coordinar las tropas que debían impedir la penetración inglesa en Castilla. Así mismo, colocaba al infante Juan de Portugal en la frontera de Extremadura, al mando de los caballeros de Santiago y de Alcántara, para impedir la invasión por aquellas tierras del rey luso ${ }^{129}$. La campaña anglo-lusa entre 1386-1387 fue un fracaso; Juan de Gante embarcaría en Porto rumbo a Bayona.

João I pudo cercar Melgaço en el Miño, a principio de 1388 y Campo Maior en el Alentejo, en septiembre-diciembre ${ }^{130}$. El condestable Pereira arrasaba Villanueva del Fresno, que se despobló y, a pesar de las treguas de seis meses, en 1389 atacaba Tuy; el arzobispo de Toledo y el maestre de Alcántara llegarían tarde, "una vez rendida la villa"131. En 1392, el maestre de Calatrava Gonzalo Núñez de Guzmán fue requerido por Enrique III para atacar Portugal por Salamanca. Los maestres de Santiago Lorenzo Suarez Figueroa y el de Calatrava Gonzalo Núñez de Guzmán "hizieron juramento y pleito omenage, de ser buenos amigos toda su vida, y guardarse lealtad" ${ }^{132}$ y mantener la paz en el reino.

El maestre de Calatrava Gonzalo de Guzmán se desplazaba a Portugal, acompañado de veinte caballeros de la orden a visitar la orden de Avis, como hija de Calatrava. João I dio instrucciones al maestre de Avis de recibirles, no como sus superiores sino como huéspedes, con honroso tratamiento, pero sin dejarles visitar la institución. Según expresó, era porque tenía una bula papal por la que Avis era libre de la tutela de Calatrava,

\footnotetext{
127 Gomes, “Observações em torno das Chancelarias”, p. 165.

${ }^{128}$ AntT, 0930, Núcleo Antiguo (NA), no 39, ff. 46r-48r, cit. SÁnchez Sesa, p. 449.

129 SuÁrez, Juan I, p. 188.

130 Oliveira; Monteiro, Historia medieval de Portugal, p. 194.

131 Torres, Crónica de Alcántara, vol. II, f. 172.

132 Rades, Crónica de las tres Órdenes, Calatrava, vol II, f. 53r.; Santiago, f. 54r.
} 
Bula que no mostraron a los calatravos. Estos excomulgaron al maestre de Avis y a sus caballeros, "por conspiradores y rebeldes" y se tornaron a Castilla13.

\section{8. Última década del siglo XIV. Guerra y treguas}

En 1388 se firmaba en Bayona un acuerdo entre Juan I de Castilla y los duques de Lancaster, por el que estos renunciaban a sus pretensiones castellanas y se preveía el enlace entre el heredero castellano Enrique y Catalina, hija de los duques. Entre 1389 y 1393 se firmarían varias treguas entre Castilla y Portugal, como la de Monção en 1389 y la última en Lisboa en mayo de 1393, por quince años, en las que el prior del Hospital Gonçalves Camelo actuaría como garante de las cláusulas contractuales ${ }^{134}$, aunque en febrero de 1396 se acordaría otra, de cuatro meses. La firmarían el condestable, el obispo de Coimbra, así como Lorenzo Suárez Figueroa y Ruy López Dávalos, renovada en diciembre por el mismo plazo. En 1399 se aprobarían otras, pues el apoyo en 1397 de Enrique III al infante Dinis, las revocó ${ }^{135}$.

A pesar de ello, la guerra de desgaste seguiría. Así, según Rades, esas operaciones de daños al enemigo llevaron al maestre de Cristo Nuno Rodrigues Freire, en 1394, a tomar Valencia de Alcántara, a donde acudió el maestre de Alcántara Martín Yáñez para defenderla y atacar territorio portugués, aunque Torres en su Crónica de Alcántara lo niega $^{136}$. Así mismo, en mayo de 1396, sin tener en cuenta las treguas, con la excusa de una deuda de doscientas cincuenta mil doblas, los portugueses atacaron y tomaron la ciudad de Badajoz y la retuvieron durante varios años ${ }^{137}$.

En 1397, el infante Dinis de Portugal, con las órdenes de Santiago y Alcántara y sus maestres, Lorenzo Suárez Figueroa y Fernán Rodríguez Mejía/de Villalobos, hicieron lo mismo en la Beira y Moura y Serpa, en el Alentejo, contestada por el condestable Pereira y el maestre de Avis, que entraron por Alburquerque ${ }^{138}$. El condestable y el maestre portugués de Santiago volvieron a entrar atacando el castillo de Feria, repelido por las órdenes de Alcántara y Santiago. Se firmaron treguas por nueve meses; por Castilla firmó el maestre de Santiago, Suárez de Figueroa. João I, en junio, volvía a "rogar a los caballeros, peones y ballesteros de las tierras del maestrazgo de la orden de Cristo que permanecieran atentos a las incursiones castellanas, pese al vigente periodo de tregua"139. En enero de 1399, Enrique III ordenaba a sus tesoreros mayores que exigieran a los maestres de las órdenes militares de Castilla, el pago de treinta mil florines para la guerra

\footnotetext{
133 IBIDEM, Calatrava, f. 63r.

134 Costa P, "A Ordem Militar do Hospital em Portugal”, p. 200.

135 Olivera, "Pax in Bello", p. 57, nota 49.

136 Rades, Crónica de las tres órdenes, Alcántara, f. 33v; Torres, Crónica de Alcántara, vol. II, ff. 173174.

137 Mazo, El condado de Feria, doc. 10.

138 Torres, Crónica de Alcántara, vol. II, ff. 186-188; Lopes, Chronica del Rey D. Ioam I, II, p. 348.

139 ANTT, CE, Caixa 32, no 44, cit. SÁNChez SESA, "Cisma, religión y propaganda”, p. 458.
} 
con Portugal ${ }^{140}$; reaccionaba al atacar Beja, Moura, Serpa y el Campo de Ourique. En ese año, se asaltó Alcántara, donde estaban los caballeros de la Orden con su maestre Fernán Rodríguez Mejía, que respondería "haciendo guerra a sangre y fuego, y habiendo tomado la villa de Peñamocor, dieron la vuelta a Castilla" ${ }^{141}$. En agosto se conquistó Miranda y en septiembre el maestre de Santiago Lorenzo Suárez de Figueroa sitiaba Noudar, que se rindió. Y todo esto sucedía mientras en Villanueva de Bancarrota se reunían los embajadores de los dos países, entre recelos, para definir treguas duraderas u otros mecanismos para el entendimiento entre los dos reinos, después de reuniones previas en esa villa y en Olivenza, en febrero de 1398. Se daba paso a las misiones diplomáticas, después de los enfrentamientos. En la etapa crucial de estas conversaciones, en un primer momento en diciembre, intervendrían por parte portuguesa el condestable Nuno Alvares Pereira y el obispo de Coimbra y, por parte castellana el maestre de Santiago Lorenzo Suárez de Figueroa y el camarero mayor y adelantado Ruy López de Ávalos. El punto fundamental en estas negociaciones sería el reconocimiento de la legalidad de João I.

Las tropas portuguesas, con el condestable Pereira y el maestre de Avis Lopo de Sousa, volvieron a invadir Extremadura, en mayo de 1400, en la que cercó Valencia de Alcántara, defendida por la orden de Alcántara y varios miembros de los linajes lusos pasados a Castilla, como los Acuña y Camelo ${ }^{142}$. En agosto, serían las milicias de las órdenes castellanas de Santiago y del Hospital las que atacarán el castillo portugués de Noudar, ya que informarán de la situación de la fortaleza al rey Enrique III, mediante una carta enviada por el maestre de Santiago ${ }^{143}$.

En 1398-1399, se produjo otra emigración de portugueses a Castilla, al haber apoyado a D. Dinis, en contra de Joao I y por el descontento de la nobleza por la política de confiscación de tierras de la Corona, al no cumplir el rey lo prometido en las Cortes de Coimbra de 1384. Los linajes da Cunha, Pacheco, Coelho y Pimentel, entre otros, pasarían a Castilla; todos desempeñarían un papel relevante en la Castilla del siglo XV ${ }^{144}$. También lo haría en enero de 1399 el prior del Hospital Alvar Gonçalves Camelo, que retornaría en septiembre de 1398. En este siglo, estos exilios se veían favorecidos por la inexistencia de convenios de extradición.

\section{Consecuencias en la frontera}

Las confrontaciones fronterizas entre Castilla y Portugal en el siglo XIV, ocasionaron la destrucción y la muerte en la "raya" y trajeron consecuencias muy negativas para la frontera, para los bienes, casas, propiedades o infraestructuras y las poblaciones a

\footnotetext{
140 SuÁrez, Relaciones entre Portugal y Castilla, p.114, doc. 17, 1399, enero 15, Illescas; p. 25, doc. 20, 1399, junio 9, Segovia.

141 Torres, Crónica de Alcántara, vol. II, f. 193.

142 Oliveira; Monteiro, Historia medieval de Portugal, p. 194; Silva, “A Ordem de Cristo”, p. 56.

143 SuÁrez, Relaciones entre Portugal y Castilla, p. 130, doc. 29, 1400, agosto 30, Jerez de los Caballeros.

144 Oliveira; Monteiro, Historia medieval de Portugal, pp. 198-199; Romero, Señores de dos reinos, p. 12.
} 
ambos lados de la frontera, en particular en la zona de Badajoz-Elvas. Tenemos como ejemplo los prisioneros tomados en las cabalgadas, así como las levas o reclutamiento de brazos productivos, como los mil peones que se exigían a Fregenal o los cuatro mil a las Sierras de Aroche y Constantina ${ }^{145}$.

En la frontera castellana se encontraban los señoríos de las órdenes militares de Alcántara y de Santiago, así como los de los condes de Alburquerque y de Feria. Estas dos Compañías y las de Avis y del Hospital verían sus territorios atacados constantemente, saqueando sus lugares y cultivos, pues era uno de los pasos más utilizados en las incursiones y en el camino hacia Lisboa. En Portugal, la región más castigada fue sin duda la de la frontera del Alto Alentejo, donde las órdenes tenían señoríos importantes.

Los dominios de la orden de Cristo estaban entre Mondego y el Tajo; los de la orden de Santiago al sur del Tajo, en el Alentejo y en el Algarve. Los del Hospital y de Avis se encontraban en el Alto Alentejo, con su centro en Crato la primera y entre Coruche y Elvas -que pertenecía a la orden de Cristo-, con Noudar para Avis ${ }^{146}$.

Muchos episodios de saqueo y pérdidas patrimoniales y humanas se produjeron en este siglo en lugares fronterizos, como en la guerra de 1336-1340, en las regiones de Barroso, Montalegre y Monforte de Río Livre, que obligaron a Afonso IV a concederles privilegios y moratorias para evitar la despoblación. Ocurría lo mismo en la zona de Badajoz y en la raya del Guadiana, que se reproducirá en Aroche, Aracena y Cortegana, o lugares como Lobón en territorio santiaguista o Zarza la Mayor en el alcantarino, que estaban abandonados en 1356, así como otros en la misma zona en $1366^{147}$. Pero, estos actos no sólo se producían por incursiones enemigas, sino que también por ejércitos aliados, como los del conde de Cambridge, que en 1386 arrasaron los bienes de los habitantes del Alentejo ${ }^{148}$.

En otros casos, como cuando João I quería recuperar Chaves, pasada al enemigo, en el primer cuatrimestre de 1386, mandaba sus tropas a territorio castellano para conseguir alimentos y ganado, internándose entre ocho y diez leguas en Galicia. Indudablemente, los castellanos hacían lo mismo en territorio luso, como en Moura, de lo que se quejaban sus pobladores ${ }^{149}$.

Estos hechos no fueron negativos para todos, pues se muestran diversos actos de compra-venta en lugares de frontera, que revelan el interés, a pesar de esa situación, de señores de hacerse con tierras lo más extensas posibles y aumentar su patrimonio.

\footnotetext{
${ }^{145}$ Martín, "La frontera hispano portuguesa", p. 40.

146 Costa A, "As Órdens Militares em combate", p. 14.

147 Monteiro, "Arcaísmo o modernidade no Exército Português", p. 262; MARQUES, "Relações fronteiriças luso-castelhanas", p. 110.

148 Monteiro; Martins, As cicatrizes da guerra, pp. 81-82.

149 IBIDEM, pp. 80-81.
} 
Sería el caso del "conde de Feria que entre 1396 y 1399 se manifestaba como el más activo comprador de territorios entre el concejo de Badajoz, los de la orden de Santiago y los de su señorío". También lo haría como comprador la orden de Santiago, pues su comendador de Guadalcanar Alvaro Alponte adquiría tierras en nombre de su maestre Lorenzo Suárez de Figueroa, aunque "estaba dagnificada y no rentava cosa alguna por cabsa de las guerras que era entre Castilla y Portugal" 150 .

A los abandonos poblacionales se unían los efectos dañinos sobre la producción agraria y los consecuentes problemas de abastecimiento a los núcleos urbanos. Hechos que se intentaron subsanar por las autoridades, los primeros los monarcas; así se menciona la ayuda de la Corona a la ciudad de Badajoz en 1370 con la emisión de privilegios para afrontar el problema de la despoblación; lo mismo ocurría en Coria, en 1386, que por una misiva de Juan I favorecía a trescientos vecinos para establecerse en la villa. Pero no fueron los únicos, pues los nobles ayudaron en el mismo sentido, como en 1380 en el señorío de Alburquerque, mediante exenciones fiscales. Idéntica actitud tendrían las órdenes militares en las poblaciones de sus señoríos ${ }^{151}$.

Lo mismo ocurría en el lado portugués con las cabalgadas de los fronteros castellanos, como la orden de Santiago sobre Elvas, Campo Mayor y Penamacor. Se documentan privilegios y exenciones para la población que quisiese instalarse en las zonas abandonadas por razones de guerra, como Juromenha o Marvao, que recibían un privilegio de Pedro I, en 1361, por esa razón o bien Castelo Rodrigo en 1382, Guarda en 1385, Monsanto en 1389, Ouguela en 1391 o en Alcoutim en 1397, por João I. Pero no sólo se producían esas donaciones, sino que para paliar esos abandonos, los reyes proveían esos territorios de cotos de homiziados, como fue el caso de Arronches en 1385 y de Juromenha en 1386. Igualmente, se privilegiaba a aquellos que quisieran quedarse en el interior de las fortalezas de la frontera; sería el caso de Moura en 1361 o de Silves en $1372^{152}$.

Efectos similares se producían en la actividad comercial, base fundamental de la economía en tiempos normales, que en la frontera tenía una gran animación, en particular con las ferias existentes a lo largo de ella, con una mención especial a la de Medina del Campo, con intensos intercambios de todo tipo de productos, excepto los vedados para la exportación, como oro, plata, monedas, armas, caballos o grano. Hay que tener en cuenta el comercio clandestino, de contrabando, que ocupaba a una parte de la población de la frontera, sobre todo con los caballos ${ }^{153}$. Todo esto desaparecía en gran parte en los momentos de guerra; no obstante, siempre quedaba una mínima actividad, no oficial.

\footnotetext{
${ }_{150}$ Archivo Ducal de Medinaceli (ADM), Secc. Feria, leg. 26, doc. 50 y Real Academia de la Historia (RAH), col. Salazar, M-5, ff. 20r y 102v, cit. Montaña, "E Levaram Captivos", p. 22.

151 IBIDEM, pp. 22-23.

152 Monteiro; Martins, As cicatrizes da guerra, p. 86.

${ }^{153}$ IBIDEM, p. 70. Se daba la paradoja de que varios lugares del señorío de la orden de Avis tenían dificultades para encontrar caballos, cuando la misma orden tenía en Alandroal, en el Alentejo, una yeguada de cuarenta cabezas.
} 


\section{Conclusiones}

El objetivo fundacional de las órdenes militares era su contribución en la lucha contra los infieles, los musulmanes, lo que no fue óbice para participar en las luchas internas de los reinos de Castilla o de Portugal y en otros litigios con Aragón o Navarra, siguiendo una parte del proceso de lo que el profesor Ayala nombra como secularización de las órdenes militares. En ellos, se esforzarán en colaborar con los reyes correspondientes, a favor de sus reivindicaciones dinásticas o territoriales, acompañando a sus maestres, que por el mismo proceso, serán miembros de la alta nobleza o próximos a ella, en lo que, secundando a Enrique Rodríguez-Picavea, también se podría llamar señorialización de las mismas.

La participación de las órdenes militares en los conflictos armados, patrocinados y animados por los monarcas castellanos y portugueses, se sucedieron a lo largo de los siglos XIII al XV, en una evolución que era el reflejo de la de la propia monarquía, que les llevará a enfrentarse entre sí, con una única y extraordinaria excepción: la batalla del río Salado o de Tarifa. Esta es el ejemplo de una batalla campal o abierta en la Edad Media. Hubo una planificación previa, un planteamiento exitoso con la distribución de los cuerpos de ejército, tanto por parte cristiana como musulmana, con una cierta coordinación y disciplina, no siempre seguidas, pues los combates no se ajustarían a lo previsto. Pero, el resultado de la batalla estuvo marcado por el azar de los hechos; los cristianos tuvieron quizás más suerte, aunque su caballería dominó el combate y permitió la victoria final. Por ello, ese tipo de batallas era una salvedad; predominarán las batallas o guerras de fronteras.

En lo referente al papel de las órdenes militares en la batalla del Salado, es un hecho relevante que fuese la primera y única vez que estas milicias de los dos reinos al completo se encontraban y peleaban juntos por la misma causa. Aunque hubo otra acción conjunta, pues, antes, en el marco de la campaña contra los infieles que culminó con la conquista de Teba, en 1329-1330, el maestre de la orden de Cristo participó con un contingente portugués de quinientos caballeros ${ }^{154}$.

Esta colaboración no existió antes del Estrecho/Salado y tampoco tuvo una continuación efectiva en los siguientes tiempos ya que, una vez se desvaneció su influencia, volvieron las peleas de frontera y, lógicamente, las órdenes militares de los dos reinos se volvieron a enfrentar. Seis años después de Teba se iniciaba la guerra luso-castellana, en la que la orden de Avís lucharía contra la de Alcántara. A señalar otra excepción, en la que estas órdenes compartieron pacíficamente un evento, la boda de Juan I de Castilla con la infanta Beatriz de Portugal, en Elvas-Badajoz, en 1383.

La culminación de los desencuentros llegaría con dos casos de sucesión de los reinos en cuestión, con la batalla de Aljubarrota en 1385 y la guerra de Sucesión castellana, entre 1475 y 1479 , en las que se afrontaron en batallas campales los dos ejércitos, en donde estaban integradas esas milicias.

${ }^{154}$ Ayala, "Órdenes militares y frontera", p. 269. 
Las órdenes militares estarán divididas en cuanto al seguimiento de uno u otro bando en las guerras. Hemos podido constatar esos desacuerdos, que llevaron al exilio a algunos de sus maestres o a destituciones. Así, vemos que la orden portuguesa del Hospital de San Juan tenía o seguía criterios propios, seguramente por el hecho de no estar administrada, gobernada o dirigida por un maestre de la casa real o por ser una orden internacional, pues se destacó del resto de las órdenes nacionales en dos de los hechos destacados. Así, el prior de Crato, maestre de la orden, Pedro Álvares Pereira ${ }^{155}$, estuvo en el bando de la reina Beatriz de Portugal y de su esposo el rey Juan I de Castilla, en la guerra de sucesión de Fernando I y después de la batalla de Aljubarrota la sede de la orden fue tomada por el rey João I. Igualmente, en el litigio de la regencia de Afonso V, el prior de Crato, Nuno Gonçalves de Góis, tomó el partido de la reina viuda doña Leonor de Aragón, frente al otro regente, el infante don Pedro, que se apoderaría de la sede en 1441.

Estamos pues en unas operaciones en las que las órdenes militares participaron por designio y voluntad de los monarcas castellanos o portugueses, en la defensa de los territorios y de los patrimonios de dichos reinos y, en el caso de la batalla del Salado, también de su fe. Reaccionarán enfrentándose en movilizaciones o altercados de frontera, en los que sus bienes serán atacados directamente, en particular las órdenes de Santiago y de Alcántara, en el lado castellano y las órdenes de Avis, Santiago, Cristo y el Hospital en el portugués.

Siguiendo al profesor Monteiro, podríamos decir que los ejércitos en conflicto no estaban obsoletos, en cuanto a tácticas, desarrollos y resultados finales, sino que asimilaron las enseñanzas recibidas en sus contactos con las mesnadas francesas e inglesas, veteranas de la Guerra de los Cien Años. Y que la participación de las órdenes militares en las guerras que enfrentaron los reinos de Castilla y Portugal fue muy eficiente y los monarcas supieron apreciar esa contribución premiando a las órdenes y a sus maestres ${ }^{156}$. De la importancia de las órdenes militares para los monarcas se puede mostrar lo dicho por João I -en palavras de Fernão Lopes -, que "o meestrado de Christus e de Santiago e o dAvis e o priol do Esprital que sam asy como quatro collunas que sostem a honrra de meu reyno"157.

Las consecuencias negativas de estas guerras del siglo XIV se dejaron ver principalmente en la frontera. Pero, no sólo fue allí donde repercutió gravemente, sino que fue la nobleza la que suportó las mayores secuelas. Las guerras civiles y la de sucesión de Fernando I supusieron la pérdida de muchos linajes o su declive y la aparición de una nobleza nueva, alrededor de Enrique II y la nueva dinastía, que sería promocionada con su puesta al servicio del rey. Como lo sería la batalla de Ajubarrota, con la desaparición de una gran parte de los linajes castellanos. Estos conflictos serían pues los causantes de cambios profundos en la Castilla de finales del siglo XIV: militares, hacendísticos, burocráticos, que acrecentarán el poder de la monarquía y llevarán en

\footnotetext{
155 SÁnChez SeSA, "Cisma, religión y propaganda”, p. 448. Hijo bastardo del arzobispo de Porto y hermano del condestable Nuno, fue absuelto por Clemente VII de todos los impedimentos para poder ser prior del Hospital.

156 Monteiro, "Arcaísmo o modernidade no Exército Portugués", pp. 274-275.

157 Lopes, Crónica de D. João I, vol. II, p. 402.
} 
el siglo XV al Estado Moderno con los Reyes Católicos. Otras consecuencias serían las expatriaciones de nobles, en los dos sentidos.

En el siglo XIV se pondría de relieve en ambos reinos el concepto de "sueño de unión ibérica", unificación de Castilla y Portugal, como continuación del escenificado en la agrupación de Castilla y León en el siglo XIII. Así fue con los enlaces matrimoniales previstos por las monarquías, que nos llevarían a Fernando I en sus ambiciones castellanas y a Juan I con la corona portuguesa, aunque tanto uno como otro fracasaron en sus iniciativas. En este último conflicto, el objetivo de João I fue su legitimación y la de su dinastía, en el marco de su independencia de Castilla. El siglo XV vería la prolongación de esas aspiraciones de unión, con los mismos mecanismos y que conducirían a la guerra de sucesión castellana por Afonso V de Portugal, planificadas pacíficamente por los Reyes Católicos y Manuel I al final del siglo.

\section{Bibliografía}

Ayala Martínez, Carlos de, "Órdenes militares y frontera en la Castilla del siglo XIV", La España Medieval, 23 (2000), pp. 265-291.

Ayala Martínez, Carlos de, Las Órdenes Militares Hispánicas en la Edad Media (siglos XII-XV), Marcial Pons, Madrid, 2003.

Ayala Martínez, Carlos de, "Pedro I y las órdenes militares", Memoria y civilización, 22 (2019), pp. 63-92.

BARquero GoÑI, Carlos, "Disputas por el priorato del Hospital en Castilla, ss. XIV-XV", Hispania, 199 63/2 (1998), pp. 537-557.

Corral VAL, Luis, "La orden de Alcántara durante la Edad Media, según la documentación pontificia”, Hispania Sacra, 50 (1988), pp. 5-34.

Cosme, João dos Santos Ramalho, "O reflexo das rivalidades luso-castelhanas no espaço Raiano (1165-1580). O caso dos concelhos de Moura, Mourão, Olivença e Serpa", Revista de Estudios Extremeños, 48.2 (1992), pp. 377-404.

Costa, António Carlos Martins, "As ordens militares em combate nos finais da Idade Média: o caso da guerra de Susessão de Castela (1475-1479)", Medievalista online, 19 (2016), pp. 1-32.

Costa, Paula Pinto, "A Ordem Militar do Hospital em Portugal: Dos Finais da Idade Média à Modernidade", Militarium Ordinum Analecta, Fonseca, Luís Adão de (dir.), Fundação A. de Almeida, Porto, 1999-2000, t. 3/4, pp. 1-619.

Costa, Paula Pinto, "As adaptações das Ordens Militares aos desafíos da Crise tardomedieval", Historia, III série, 5 (2004), pp. 143-154.

Crónica de Portugal de 1419, Adelino de Almeida Calado (ed.), Aveiro, 1998, cit. Montaña, "E Levaram Captivos e derribaram o logar todo. La guerra en la frontera castellano-portuguesa (siglos XIV-XV)”, Norba, (2008), pp. 11-28. 
Cunha, Maria Cristina, "A Ordem de Avis e a monarquia portuguesa até ao final do reinado de D. Dinis”, Revista da Facultade de Letras, 12 (1995), pp. 113-124.

Cunha, Maria Cristina, "A filiação da Ordem de Avis em Calatrava. Algumas notas a propósito da visita da 1346", As ordens militares e as ordens de cavalaria na construção do mundo occidental, Fernandes, Isabel C. (coord.), Ed. Colibri, Pamela, 2002, $4^{\circ}$ Encontro, pp. 317-326.

Delaville Le Roulx, Joseph, Les hospitaliers à Rhodes jusqu'à la mort de Philibert de Naillac, 1310-1421, E. Leroux, Paris, 1913, Variorum reprints, Londres, 1974.

Fernandes, Isabel Cristina; Oliveira, Luís Filipe, "Las Órdenes Militares en el Reino de Portugal", Las Órdenes Militares en la Europa medieval, Novoa Portela, Feliciano; Ayala Martínez, Carlos de (eds.), Lunwerg, Barcelona, 2005, pp. 137-165.

Ferrer i MAllol, $M^{\mathrm{a}}$ Teresa, "L'infant Martí i un projecte d'intervenció en la guerra de Portugal (1381)", VIII Congreso de Historia de la Corona de Aragón, 3, 1973, pp. 205-233.

GARCíA FERnÁNDEz, Manuel: "Las relaciones internacionales de Alfonso IV de Portugal y Alfonso XI de Castilla en Andalucía: La participación portuguesa en la batalla del Estrecho 1325-1350", Actas das II Jornadas luso-espanholas de História Medieval, Porto, 1 (1987), pp. 201-216.

GARCÍA FITz, Francisco, Ejércitos y actividades guerreras en la Edad Media europea, Arco Libros, Madrid, 1998.

García Fitz, Francisco, "Nuevos desencuentros. Las paces de Alcoutim (1371) y Santarém (1373)", Encuentros y Desencuentros Ibéricos. Tratados Hispano-portugueses desde la Edad Media, Novoa Portela, Feliciano; Martim de Albuquerque (coords.), Lunwerg, Barcelona, 2006, pp. 51-61.

García Fitz, Francisco, "Las guerras de cada día” en la Castilla del siglo XIV”, Edad Media, Revista de Historia, 8 (2007), pp. 145-181.

García Fitz, Francisco; Monteiro, João Gouveia (eds.), War in the Iberian Peninsula, 700-1600, Routledge, Abingdon, 2018.

Gomes, Saul António, “Observações em torno das Chancelarias das Ordens Militares em Portugal na Idade Média", As ordens militares e as ordens de cavalaria na construção do mundo occidental, Fernandes, Isabel C. (coord.), Ed. Colibri, Pamela, 2002, $4^{\mathrm{o}}$ Encontro, pp. 111-167.

GonzÁlez Mínguez, César, "La reacción oligárquica frente al poder de las monarquías (1284-1325)", Historia de España de la Edad Media, Álvarez Palenzuela, Vicente Ángel (coord.), Ariel, Barcelona, 2002.

Gran Crónica de Alfonso XI, Diego Catalán (ed.), Gredos, Madrid, 1976.

Josserand, Philippe, Eglise et pouvoir dans la Péninsule Ibérique : les ordres militaires dans le royaume de Castille (1252-1369), Casa de Velázquez, Madrid, 2004. 
Ladero Quesada, Miguel Ángel, "Formación y funcionamiento de las huestes reales en Castilla en el siglo XV", Actas de las II Jornadas Nacionales de Historia Militar, Málaga, 1993, pp. 161-172.

Lopes, Fernão, Chronica del Rey D. Ioam I de Boa Memoria e dos reys de Portugal o decimo, António Alvares, Lisboa, 1644.

Lopes, Fernão, Crónica de D. João I, Livraria Civilização, Porto, 1990.

LOPEs, Fernão, Crónica do senhor rei dom Fernando nono rei destes regnos, Livraria Civilizaçao, Porto, 1966.

López de Ayala, Pero, Crónica del Rey D. Pedro y del Rey D. Enrique, INCIPIT, Buenos Aires, 1994.

LóPEz FERnÁNDEZ, Manuel: "Las órdenes religioso-militares en las fronteras de Tarifa (1273-1388)", Al Qantir, 12 (2012), p. 54-65.

López Fernández, Manuel, "Los Mexia en la encomienda mayor de León de la orden de Santiago", Norba, 31 (2018), pp. 143-164.

MARQues, José, “O Conselho alentejano de Figueira e a ordem de Avis, en 1336”, Revista da Faculdade de Letras de Porto, 5 (1988), pp. 95-111.

MArQues, José, "Relações fronteiriças luso-castelhanas, nos séculos XIV-XV", Ibéria: Quatrocentos/ Quinhentos, duas décadas de catédra. Homenajem a L. A. Fonseca, CEPESE, Porto, 2009, pp. 91-141.

Martín Martín, José Luis, "La frontera hispano portuguesa en la guerra, en la paz y en el comercio", Relaciones entre Portugal y Castilla en la época de los descubrimientos y la expansión colonial, Carabias Torres, Ana María (ed.), Universidad de Salamanca, 1994, pp. 29-52.

Martins, Miguel Gomes, "As hostes das ordens militares em Portugal entre os finais da reconquista e inícios do século XV - Composição e dimensão", Entre Deus e o Rei. O mundo das ordens militares, Fernandes, Isabel C. (coord.), Palmela, 2018, Coleção Ordens Militares 8.1, pp. 321-336.

Martins, Miguel Gomes; Monteiro, João Gouveia, "Portugal. II. The Late Middle Ages 1249-1367: A time of reforms and royal consolidation”, en García Fitz, Francisco; Monteiro, João Gouveia (eds.), War in the Iberian Peninsula, 700-1600, Routledge, Abingdon, 2018, (pp. 212-222).

Martins, Rui Cunha, "La frontera medieval Hispano-Portuguesa (el punto de vista de la guerra)", en Vaca, Ángel (coord.), La guerra en la Historia, Universidad de Salamanca, 1999, pp. 95-113.

Mazo Romero, Fernando, El condado de Feria (1394-1505). Contribución al estudio del proceso señorializador en Extremadura durante la Edad Media, Institución P. de Valencia, Badajoz, 1980. 
Montaña Conchiña, Juan Luis de la, "E Levaram Captivos, e derribaram o logar todo. La guerra en la frontera castellano-portuguesa (siglos XIV-XV)", Norba, (2008), pp. 11-28 Monteiro, João Gouveia, “Arcaísmo o modernidade no Exército Português nos finais da Idade Média? O contributo das, Ordens Militares”, Ordens Militares. Guerra, religão, poder e cultura, Fernandes, Isabel C. (coord.), Ed. Colibri, Palmela, 1998, $3^{\circ}$ Encontro, t. II, pp. 259-275.

Monteiro, João Gouveia, A guerra em Portugal nos finais da Idade Média, Ed. Noticias, Lisboa, 1998.

MonteIro, João Gouveia, "A Fronteira Luso-Castelhana nas preocupações militares da Monarquia Portuguesa (1350-1450)", Revista Militar, 52.2/3 (2000), pp. 133-151.

Monteiro, João Gouveia; Martins, Miguel Gomes, As Cicatrizes da Guerra no Espaço Fronteiriço portugués (1250-1350), CHSC, Coimbra, 2010.

Moxó, Sebastián, "De la nobleza vieja a la nobleza nueva. La transformación nobiliaria castellana en la baja Edad Media", Cuadernos de Historia, Anexos a la Revista Hispania, III (1969), pp. 1-210.

Novoa Portela, Feliciano, "Los maestres de la orden de Alcántara durante los reinados de Alfonso XI y de Pedro I”, HID, 29 (2002), pp. 317-335.

Novoa Portela, Feliciano; Ayala Martínez, Carlos de (ed.), Las Órdenes Militares en la Europa medieval, Lunwerg, Barcelona, 2005.

Oliveira, António Resende de; Monteiro, João Gouveia, Historia medieval de Portugal (1096-1495), EUG, Granada, 2018.

Olivera Serrano, César, "Pax in Bello: la difícil paz entre Castilla y Portugal (13691431)", Vínculos de Historia, 7 (2018), pp. 46-60.

Orozco, Pedro de; Parra, Juan de la [Primera] Historia de la Orden de Santiago. Manuscrito de la RAH, Diputación de Badajoz, 1978, cit. López Fernández, Manuel, "El maestrazgo de Alfonso Méndez de Guzmán en la Orden de Santiago (1338-1342)", HID, 44 (2017), pp. 151-178.

PINA, Rui de, Chronica d'El-Rei Dom Afonso o Quarto, P. Craesbeeck, Lisboa, 1653.

PInA, Rui de, Crónica de D. Dinis. Livraria Civilizaçao, Porto, 1945.

Rades y Andrada, Francisco de, Crónica de las tres Órdenes de Santiago, Calatrava y Alcántara, El Albir, Barcelona, 1980.

Rodríguez Amaya, Esteban, "Bodas de Juan I de Castilla y Beatriz de Portugal (1383)", Revista de Estudios Extremeños, 4.1-2 (1948), pp. 67-93.

Rodríguez-Picavea Matilla, Enrique, "Caballeros calatravos y linajes castellanos (mediados siglo XIV-mediados siglo XV)", As ordens militares e as ordens de cavalaria entre o Occidente e o Oriente, Fernandes, Isabel C. (coord.), F. Calouste Gulbenkian, Palmela, 2006, $5^{\circ}$ Encontro, pp. 157-186. 
Rodríguez-Picavea Matilla, Enrique: “Caballería y nobleza en la Orden de Calatrava: Castilla, 1350-1450”, Anuario de Estudios Medievales, 37 (2007), pp. 711-740.

Rodríguez-Picavea Matilla, Enrique, Los Monjes Guerreros en los reinos hispánicos, La Esfera de los Libros, Madrid, 2008.

Rodríguez-Picavea Matilla, Enrique: "Diplomacia, Propaganda y Guerra Santa en el siglo XIV: la embajada castellana a Aviñón y la elaboración del discurso ideológico", Anuario de Estudios Medievales, 40/2 (2010), p. 768.

Romero Portilla, Paz, Señores de dos reinos. Los portugueses y el gobierno de Castilla en el siglo $X V$, Universidad de La Coruña, 2011.

SÁNCHEZ SesA, Rafael, "Cisma, religión y propaganda en las guerras castellano-portuguesas de la Baja Edad Media”, Hispania Sacra, 56 (2004), pp. 447-464.

SiLva, Isabel L. Morgado de Sousa e, "A Ordem de Cristo (1417-1521)", Militarium Ordinum Analecta, Fonseca, Luís Adão de (dir.), Fundação A. de Almeida, Porto, 2002, t. 6, pp. 3-503.

Soler del CAmpo, Álvaro, La evolución del armamento medieval en el Reino CastellanoLeonés y Al-Andalus (siglos XII-XIV), Publicaciones del EME, Madrid, 1993.

SousA, Bernardo Vasconcelos e, "Memória familiar e ordens militares. Os Pimentéis no século XIV", As Ordens Militares em Portugal e no Sul da Europa, Ed. Colibri, Palmeira, 1992, $2^{\circ}$ Encontro, pp. 37-49.

SuÁrez Fernández, Luis, Juan I 1379-1390, Diputación de Palencia, 1994.

SuÁrez Fernández, Luis, Relaciones entre Portugal y Castilla en la época de Enrique III. 1393-1406, CSIC, Madrid, 1960.

SuÁrez Fernández, Luis, Castilla, el Cisma y la crisis conciliar (1378-1440), CSIC, Madrid, 1960.

Torres y TAPIA, Alonso de, Crónica de Alcántara, Junta de Extremadura, Mérida, 1999. Valdeón Baruque, Julio, Enrique II 1369-1379, Diputación de Palencia, 1996.

Vasconcelos, António Pestana de, “Os Vasconcelos e as ordens militares. Algunas considerãçoes em torno de una linhagem”, As ordens militares e as ordens de cavalaria entre o Occidente e o Oriente, Fernandes, Isabel C. (coord.), F. Calouste Gulbenkian, Palmela, 2006, $5^{\circ}$ Encontro, pp. 247-258.

Vasconcelos, António Pestana de, "Nobreza e Ordens Militares Relações Sociais e de Poder, séculos XIV a XVI", Militarium Ordinum Analecta, Fonseca, Luís Adão de (dir.), CEPESE, Porto, 2012, t. 12, pp. 10-1020.

Zurita, Jerónimo, Anales de la Corona de Aragón, 1562, Canellas López, Ángel (ed.), Institución Fernando el Católico, Zaragoza, 2007. 